\title{
La gestión del utillaje de piedra tallada en el Paleolítico Medio de Galicia. El nivel 3 de Cova Eirós (Triacastela, Lugo)
}

\author{
Flaked tools management during the Middle Paleolithic of Galicia: level 3 from Cova \\ Eirós (Triacastela, Lugo)
}

Talía Lazuén (*)

Ramón Fábregas (**)

Arturo Lombera (***)

Xose Pedro Rodríguez (***)

\section{RESUMEN}

El nivel 3 de Cova Eirós constituye, por el momento, el único depósito del Paleolítico Medio en estratigrafía de Galicia. Cuenta con una datación absoluta que lo sitúa en la segunda mitad del Estadio Isotópico 5.

El conjunto lítico del yacimiento ha sido estudiado desde una perspectiva que combina el análisis de la producción, la gestión y el uso del utillaje. La producción se aborda básicamente a partir de lecturas tecnológicas y el uso se deduce de observaciones microscópicas, ambas basadas en referenciales experimentales.

Los análisis realizados revelan un sistema complejo de gestión de las materias primas (cuarzo y cuarcita), la coexistencia de sistemas de talla variados y el desarrollo de procesos de trabajo sobre madera y piel. Se documenta también el uso de elementos de proyectil fabricados sobre puntas Levallois. La asociación de este conjunto de tareas sugiere que el yacimiento conoce asentamientos con cierto grado de estabilidad residencial.

El conjunto de comportamientos técnicos reconocidos, algunos de ellos realmente complejos, y la fuerte estructuración espacial en la gestión de los recursos suponen una prueba palpable de las capacidades organizativas y cognitivas de estas poblaciones neandertales.

(*) Instituto Internacional de Investigaciones Prehistóricas de Cantabria (IIIPC), Universidad de Cantabria. Avda. de los Castros s/n. 39005 Santander. Correo e.: talialazuen@hotmail.com

(**) Grupo de Estudios para la Prehistoria del Noroeste (GEPN), Departamento de Historia I, Universidad de Santiago de Compostela. Praza da Universidade 1. 15782 Santiago de Compostela. Correo e.: ramon.fabregas@usc.es

(***) Institut Català de Paleoecologia Humana i Evolució Social (IPHES), Universitat Rovira i Virgili. Avinguda Catalunya 35. 43002 Tarragona. Correos e.:

alombera@prehistoria.urv.cat; josepedro.rodriguez@urv.cat

Recibido: 24-IX-2010; aceptado: 24-I-2011.

\begin{abstract}
The level 3 from Cova Eirós is the only well-stratified Middle Palaeolithic deposit in Galicia. It has an absolute dating that places it in the second half of OIS 5.

The lithic assemblage has been analysed in several ways, combining the management, knapping and use of the stone tools. As for the first we have resorted to a technological approach and the use was inferred from microscopic examination, in both cases interpretations being endorsed by previous experimental work.

As a result, we have found out a sophisticated system of raw material management (namely, quartz and quartzite), the coexistence of several knapping methods and working processes on wood and leather. Also, the use as projectiles of several Levallois points has been recorded. The available evidence suggests that the occupations at this level had a certain degree of stability.

The technological behaviour recorded, in some cases rather complex, and the strong spatial structuring of the resource management underline the cognitive and organizational skills of these Neanderthal groups.
\end{abstract}

Palabras clave: Pleistoceno Superior; Península Ibérica; Tecnología lítica; Huellas de uso; Caza.

Key words: Upper Pleistocene; Iberia; Lithic technology; Use-wear analysis; Hunting.

\section{INTRODUCCIÓN}

La historiografía sobre el Paleolítico antiguo -Inferior y Medio- de Galicia ha producido resultados aún muy parciales por las características del registro pleistoceno y la relativa debilidad de la investigación en la región (Vázquez Varela 
2000). Las primeras excavaciones de E. Aguirre (1964) en As Gandaras de Budiño constituyen un punto de inflexión, así como los trabajos de J. Cano Pan y su equipo (1997; Cano Pan et al. 2000), que proporcionaron un marco cronológico general a partir de los estudios de los materiales recuperados en las terrazas del Miño. La secuencia crono-cultural terminó por refutar la relativa modernidad -Pleistoceno Medio final-de la ocupación de Galicia (Estévez y Vila 1999). De hecho, se propuso un poblamiento durante el Pleistoceno Inferior a partir de los hallazgos en las terrazas altas del Miño (Cano Pan et al. 2000).

El contexto geológico gallego y sus dinámicas geomorfológicas dificultan el depósito y conservación de secuencias estratigráficas al aire libre y apenas hay formaciones cársticas que puedan albergar cuevas. El nivel 3 de Cova Eirós, objeto de este estudio, es por el momento el único nivel de Paleolítico Medio en estratigrafía excavado en Galicia. El yacimiento está en el valle del Miño, en el límite occidental del ámbito típicamente cantábrico, en una montaña caliza con relieve abrupto que da paso, hacia el oeste, a unas regiones caracterizadas por relieves más suaves en un contexto granítico y con amplias cuencas interiores surcadas por ríos largos -Miño, Sil o Tambre- que drenan hacia el Atlántico. En esta misma zona están las otras dos cuevas gallegas con ocupaciones paleolíticas, Valdavara y A Valiña (Fig. 1).

Cova Eirós se localiza en la parroquia de Vilavella, término municipal de Triacastela (Lugo), al pie de la Sierra de Ouribio, a media ladera del Monte Penedos y a unos 780 m.s.n.m. La boca se abre al noroeste. El vestíbulo de la cueva discurre en una galería de unos $20 \mathrm{~m}$ de longitud por $2 \mathrm{~m}$ de alto, cuyo recorrido total se estima en unos 104 m. J. R. Vidal Romaní dio a conocer la cavidad tras una excavación paleontológica, en el fondo de la galería, en la que se recuperaron más de 4.000 restos de Ursus spelaeus (Grandal y Vidal 1991; Grandal 1993). La secuencia arqueológica paleolítica se debe a la intervención llevada a cabo por J. Cano Pan en 1993, en el marco del "Proyecto Arqueológico Val do Sarria-Val do Mao" en busca de niveles arqueológicos del Pleistoceno u Holoceno temprano. La excavación consistió en un sondeo de $1 \mathrm{~m}^{2}$ en el vestíbulo, pegado a la pared este -según orientación teórica- donde se describen cinco niveles estratigráficos (Cano y Nogueira 1993). A partir del estudio
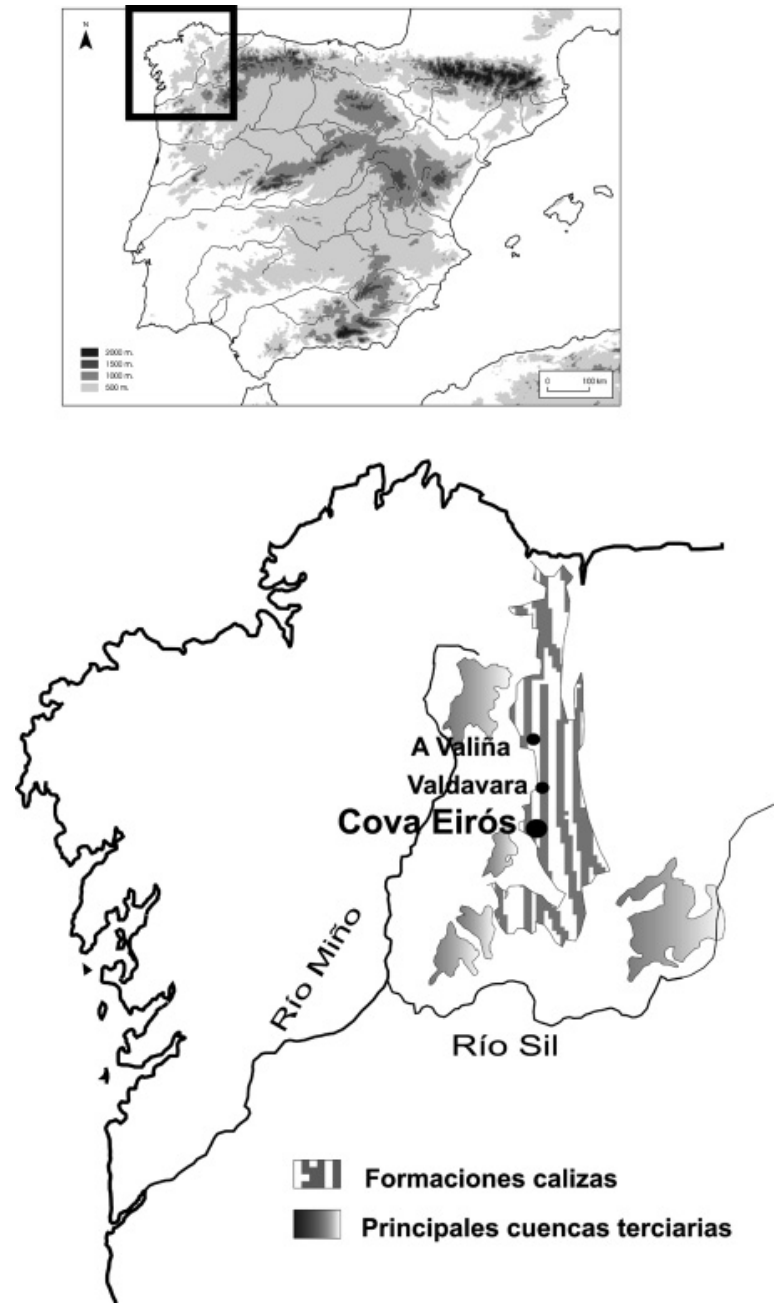

Fig. 1. Localización de Cova Eirós (Triacastela, Lugo), yacimiento del Paleolítico Medio, en la Península Ibérica y en su contexto geológico (adaptado de Santanach, 1994 y Taboada y Silva 1999). Se señalan los cercanos yacimientos paleolíticos en cueva de A Valiña y Valdavara.

de la industria lítica se sugirió una cronología del Paleolítico Superior inicial para los niveles II y III y del Paleolítico Medio para el V. Según Nogueira (1997: 28), los denticulados y la talla Levallois del nivel $\mathrm{V}$ confirmarían esa adscripción crono-cultural y "todavía más, nuestras sospechas de encontrarnos en esa etapa inicial del Paleolítico Superior" (para los niveles II y III).

En agosto de 2008 comenzaron las nuevas campañas de excavación en Cova Eirós (Lazuén et al. 2010) incluyendo en un sondeo de $4 \mathrm{~m}^{2}$ la cata realizada por J. Cano Pan en 1993. Se defi- 
nieron el nivel 2, con 169 restos líticos y 298 faunísticos, adscrito al Paleolítico Superior y el nivel 3, con 185 restos líticos y 193 restos de macrofauna, adscrito al Paleolítico Medio. El análisis de la fauna (Fábregas et al. 2010) muestra la importancia de los ungulados de tamaño mediano o medio-pequeño (ciervo, corzo, rebeco), la presencia puntual de herbívoros grandes, quizá rinocerótidos, y también de carnívoros, especialmente Ursus spelaeus. Dataciones absolutas por Optical Stimulated Luminiscence (OSL) sitúan este nivel en la segunda parte del Oxygen Isotopic Stage $(O I S)$ 5, en $84807 \pm 4919$ años BP (MAD-5612BIN). En una ampliación posterior de la excavación hacia el exterior, se han definido dos nuevos niveles que podrían ampliar la secuencia hacia cronologías más recientes (Fábregas et al. 2010).

En este artículo analizaremos la producción, gestión y uso del utillaje lítico del nivel 3 como partes de un proceso técnico que lleva desde la captación de la materia prima hasta el abandono del útil (Geneste 1991; Karlin 1991). Esta información acerca de los comportamientos técnicos documenta aspectos sustanciales de la estructura económica y social de estos grupos, tales como la organización de las actividades en los asentamientos, la explotación del territorio o el aprovechamiento de los recursos. A partir de los datos obtenidos del estudio de este conjunto lítico, nos aproximaremos a algunos de estos aspectos.

\section{APROVISIONAMIENTO DE MATERIAS PRIMAS Y PRODUCCIÓN DEL UTILLAJE DE PIEDRA}

Los sistemas de aprovisionamiento y producción del utillaje lítico muestran una gran variabilidad ya desde períodos antiguos del Paleolítico, un rasgo especialmente apreciado desde la renovación de los análisis tecnológicos en los años 1980 y 1990 (Boëda 1991). Esta variabilidad se explica por las necesidades de utillaje generadas por estos grupos -los objetivos de la producción- y la disponibilidad de la materia prima: el tipo de roca, pero también, el tamaño de los bloques originales, sus cualidades cristalinas, la presencia o no de fisuras, etc. En una perspectiva más amplia, esta variabilidad está relacionada con las dinámicas históricas del período.
El estudio de la producción del nivel 3 de Cova Eirós incluye cuatro objetivos: 1) comprender los procesos de selección, captación y gestión de las materias primas, 2) reconocer los esquemas de fabricación y determinar su grado de complejidad, 3) identificar los objetivos de la producción y 4) comprender cómo se ha organizado la gestión del utillaje. Para su consecución se han estudiado los procesos técnicos, a partir de la identificación de las materias primas empleadas y de la lectura de los atributos tecnológicos de los restos tallados (Pelegrin et al. 1988; Boëda et al. 1990; Karlin 1991; Ibáñez y González Urquijo 1996; Terradas 2001; Baena y Cuartero 2006). Esto nos permite reconstruir los procesos de fabricación del instrumental lítico y entender cómo se ha organizado esta actividad.

Las materias primas identificadas son cuarzo y cuarcita. Sus variedades internas, detectadas con criterios de visu, se relacionan con el tamaño de los bloques y con las cualidades cristalinas y grosor de los granos. Esta variabilidad ha influido en la gestión del utillaje. El paquete calizo en el que se abre Cova Eirós contiene vetas de cuarzo. Parte de la producción parece aprovechar estas vetas o los depósitos secundarios formados en los cursos de agua cercanos. Sin embargo, algunos de los cuarzos de mejor calidad, por el tamaño y homogeneidad de los bloques, proceden probablemente de otras localizaciones y formarían parte de un sistema de circulación de materiales más amplio. La disponibilidad de cuarcitas de buena calidad para la talla es desconocida por el momento en la zona. Las prospecciones realizadas en la depresión de Monforte, a unos $40 \mathrm{~km}$ hacia el suroeste en línea recta, revelan afloramientos de esta roca, aprovechados en el Paleolítico Medio, en el sector sur de esta depresión, aunque es probable que se puedan localizar otros más cercanos a Cova Eirós. El aprovechamiento más intensivo de los cuarzos y de las cuarcitas de buena calidad, en detrimento de las cuarcitas de grano grueso, es una tendencia ya observada en los yacimientos al aire libre del Paleolítico Medio en la zona centro-oriental de Galicia (Llana 1991; Lombera et al. 2008).

El conjunto lítico del nivel 3 de Cova Eirós, recuperado en la campaña de 2008, está formado por 185 elementos. Entre ellos hay un percutor y 19 cantos, bloques o plaquetas no tallados. El $88,8 \%(\mathrm{n}=165)$ de la colección es de cuarzo, el $10,2 \%(n=19)$ de cuarcita y el $1 \%(n=2)$ de 
arenisca. Si bien la variedad de materias primas empleadas es limitada, las diferencias en cuanto a las calidades a las que aludíamos deben ser tenidas en cuenta para comprender la gestión del utillaje desarrollada por los grupos humanos paleolíticos.

Como se aprecia en la Tabla 1 el grueso del conjunto está compuesto por lascas brutas $(51,5 \%)$ y restos de talla $(27,8 \%)$. Sin embargo, aparecen todos los elementos de las diferentes fases de la cadena operativa de producción de soportes aunque en porcentajes muy desiguales y con las particularidades -sobre todo por materias primasque más adelante presentaremos.

\begin{tabular}{|l|c|c|r|}
\hline & Cuarzo & Cuarcita & Total \\
\hline Núcleo & 4 & - & 4 \\
Lasca & 68 & 17 & 85 \\
Retocado & 24 & 1 & 25 \\
Punta & 4 & 1 & 5 \\
Resto talla & 46 & - & 46 \\
\hline Total & $\mathbf{1 4 6}$ & $\mathbf{1 9}$ & $\mathbf{1 6 5}$ \\
\hline
\end{tabular}

Tab. 1. Nivel 3, Paleolítico Medio, Cova Eirós (Triacastela, Lugo): relación entre materias primas y categorías tecnológicas del material tallado.

El grupo de útiles retocados (Tab. 2A) -incluyendo las puntas- supone prácticamente el $20 \%$ del total. Casi todas las piezas modificadas por retoque son de cuarzo. Las lascas retocadas(1) son las más representadas, seguidas de raederas y puntas (Fig. 2: 3, cuarcita; 4 y 5, cuarzo). También son relativamente frecuentes las piezas astilladas. Dos aparecen sobre piezas con retoque denticulado previo en alguno de sus filos conformando útiles dobles (Fig. 2: 7). En el conjunto aparecen algunos becs (Fig. 2: 9 y 10) y tipos del Paleolítico Superior, como raspadores (Fig. 2: 8) o una truncadura.

El estudio de los núcleos y soportes (Tab. 2B) muestra la alta variabilidad de las estrategias de

(1) Las raederas, denticulados, etc., son lascas retocadas, sin embargo en este caso, el concepto de "lasca retocada" se emplea para referirse a lascas que presentan algún filo modificado por series de retoques que afectan a tramos cortos, que son poco invasivos o que apenas modifican la delineación del filo y la morfología de la pieza. Por ello no pueden ser englobadas en ninguno de los tipos convencionales.

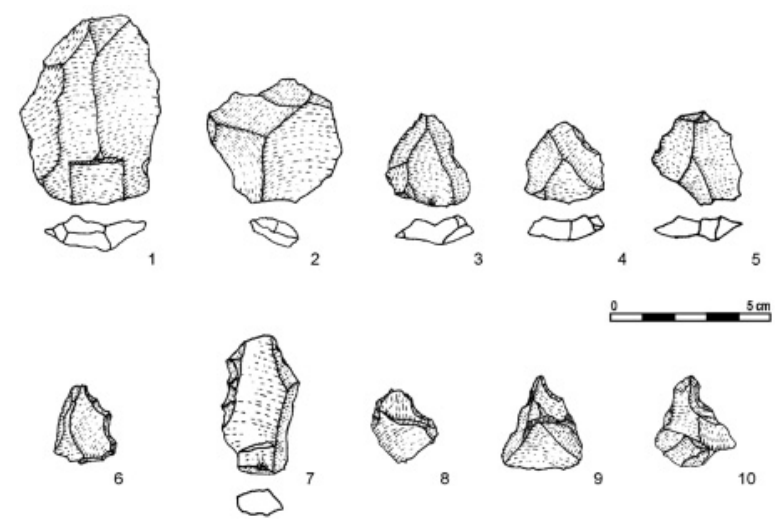

Fig. 2. Material tallado en cuarcita (1-3) y cuarzo (4-10) del nivel 3, Paleolítico Medio, Cova Eirós (Triacastela, Lugo): 1 y 2, lascas Levallois; 3, 4 y 5, puntas Levallois; 6, denticulado; 7, denticulado-astillado; 8, raspador; 9 y 10, becs. Dibujo Fátima Martínez.

producción empleadas en la fabricación del instrumental lítico. Se han identificado seis sistemas de explotación con objetivos de producción diferentes: discoide (Boëda 1993; Peresani 2003; Terradas 2003), Kombewa (Tixier y Turq 1999), Levallois (Boëda 1993), Quina (Bourguignon 1996), unipolar y bipolar. Las producciones Quina y bipolar se reconocen solo en cuarzo y la discoide solo en cuarcita. El resto está tallado en cuarzo y cuarcita.

Contamos con cuatro núcleos, tres de pequeñas dimensiones y otro de formato algo mayor. Todos son de cuarzo y están explotados a partir de estrategias muy diferentes. Uno es de tipo microlevallois $(36 \times 31 \times 13 \mathrm{~mm})$, con tres extracciones centrípetas en lo que parece un comienzo de explotación. El último negativo extraído de este núcleo es de $20 \times 24 \mathrm{~mm}$. La producción es de tipo Levallois pero sin preparación previa de la plataforma de golpeo. Una relación de planos adecuada y una buena disposición de la superficie natural la han hecho innecesaria. La ausencia de preparación busca evitar la pérdida de masa, dado el reducido tamaño del volumen original. La producción de soportes tan pequeños no necesitaría un acondicionamiento exhaustivo del núcleo por la menor exigencia técnica para la extracción de las lascas. La preparación previa del volumen y de las plataformas de golpeo tiene sentido en las producciones Levallois de soportes más grandes donde el espesor, la sección y la longitud y delineación de los filos son un elemento primordial para evitar accidentes. La obtención de soportes de tipo Levallois menores de $2 \mathrm{~cm}$ no precisa 


\begin{tabular}{|l|c|c|c|l|c|c|c|}
\hline \multicolumn{1}{|c|}{ A } & Cuarzo & Cuarcita & Total & \multicolumn{1}{c|}{ B } & Cuarzo & Cuarcita & Total \\
\hline Lasca retocada & 10 & 1 & 11 & Unipolar & 22 & 4 & 26 \\
Punta & 4 & 1 & 5 & Levallois & 5 & 4 & 9 \\
Raedera & 4 & & 4 & Bipolar & 3 & - & 3 \\
Dent./Astillado & 2 & & 2 & Discoide & - & 2 & 2 \\
Astillado & 2 & & 2 & Kombewa & 1 & 1 & 2 \\
Bec & 2 & & 2 & Quina & 2 & - & 2 \\
Raspador & 2 & & 2 & Indet. & 66 & 7 & 73 \\
Dorso & 1 & & 1 & & & & \\
Truncadura & 1 & & 1 & & & & \\
\hline Total & $\mathbf{2 8}$ & $\mathbf{2}$ & $\mathbf{3 0}$ & Total & $\mathbf{9 9}$ & $\mathbf{1 8}$ & $\mathbf{1 1 7}$ \\
\hline
\end{tabular}

Tab. 2. Nivel 3, Paleolítico Medio, Cova Eirós (Triacastela, Lugo): relación entre materias primas y tipología de los útiles retocados $(\mathrm{A})$ y estrategias de producción (B).

tanto control. Esta explotación Levallois con un aprovechamiento de convexidades naturales (sin preparación o con preparaciones muy sumarias) ya se ha documentado en otros yacimientos de Paleolítico Medio europeo, algunos con producciones de cuarzo o cuarcita (2) (Ameloot-Van der Heijden 1993; Carrión y Baena 1999; Soressi 1999; Guette 2002). La explotación de otros dos núcleos es de tipo unipolar a partir de una preparación restringida de las plataformas, aunque las dimensiones y morfología de los productos buscados presentan algunas diferencias. El primero es de pequeño tamaño $(34 \times 37 \times 22 \mathrm{~mm})$ y presenta tres extracciones con restos de un facetado para preparación de la plataforma, restringido a la zona de la que parten los levantamientos. Los soportes obtenidos son menores de $3 \mathrm{~cm}$ y más anchos que largos. En el segundo $(54 \times 42 \times 31$ $\mathrm{mm}$ ) se ha acondicionado la plataforma para obtener soportes alargados y de mayor formato. Del cuarto núcleo $(32 \times 38 \times 15 \mathrm{~mm})$ se ha obtenido solamente un soporte. No obstante aporta una información valiosa porque redunda en esa fabricación de soportes a partir de núcleos de pequeño tamaño y $\sin$ acondicionamiento previo de las plataformas donde la explotación comienza directamente sobre plataformas naturales. La ausencia de preparaciones específicas y el estadio tan inicial de la explotación impiden caracterizarla con más detalle.

(2) Delagnes, A. 1992: L'organisation de la production lithique au Paléolithique moyen, approche technologique à partir de l'étude des industries de la Chaise-de-Vouthon. Tesis de l'Université de Paris X.
Muchos soportes presentes en el yacimiento proceden de explotaciones microlevallois y, sobre todo, unipolares pero hay otros de sistemas de talla Levallois, Quina, discoide o Kombewa. La dificultad de lectura de las aristas y de las direcciones de las extracciones -que en ocasiones siguen parcialmente planos de fractura interna- han llevado al límite la posibilidad de reconocimiento del sistema de talla, sobre todo para el cuarzo ( $c f$. Bracco 1997). Otros soportes no responden a esquemas de talla característicos o sistematizados.

La cuarcita se asocia fundamentalmente a estrategias de producción muy específicas: discoide, Kombewa y Levallois. El cuarzo no queda fuera de estas producciones, excepto en el caso de la talla discoide que solo está representada por dos elementos, y no resulta demasiado significativo.

El esquema de producción más representado en los soportes es el unipolar. Los productos procedentes de otros sistemas de explotación característicos, como Levallois, discoide, Kombewa o Quina, son muy escasos (Tab. 3). Hay 23 elementos elaborados a través de un esquema unipolar, con una importante preparación de las plataformas. Se conservan dos talones facetados, ocho lisos, un diedro, un machacado y tres con planos naturales o corticales. Prácticamente la mitad de los soportes obtenidos a partir de este esquema de fabricación $(n=12)$ son de plena producción, sin córtex en la cara dorsal. El resto conserva parte de la corteza del canto original, pero en ningún caso son elementos de apertura de la cara de lascado.

Diferenciamos dos grupos de soportes según el formato: menor de $3 \mathrm{~cm}(\mathrm{n}=6)$ y mayor de 4 


\begin{tabular}{|l|c|c|c|r|}
\hline & Lasca & $\begin{array}{c}\text { Retoca- } \\
\text { do }\end{array}$ & Punta & Total \\
\hline Unipolar & 16 & 7 & & 23 \\
Levallois & 5 & & 3 & 8 \\
Bipolar & 1 & 2 & & 3 \\
Discoide & 2 & & & 2 \\
Kombewa & 2 & & & 2 \\
Quina & 1 & 1 & & 2 \\
Indet. & 58 & 15 & 2 & 75 \\
\hline Total & $\mathbf{8 5}$ & $\mathbf{2 5}$ & $\mathbf{5}$ & $\mathbf{1 1 5}$ \\
\hline
\end{tabular}

Tab. 3. Nivel 3, Paleolítico Medio, Cova Eirós (Triacastela, Lugo): relación entre soportes y estrategias de producción.

$\mathrm{cm}(\mathrm{n}=4)$ grosso modo (Fig. 3). Posiblemente asociado al formato de los soportes encontramos diferencias en su modificación por retoque. En el grupo de los de menos de $3 \mathrm{~cm}$, el más numeroso, hay solo dos retocados (una lasca retocada y un raspador). Todos los soportes de mayor formato han sido conformados a través de retoque excepto la única lasca de cuarcita.

Destacamos la producción Levallois dentro del conjunto general por su amplia variabilidad interna. Hay, al menos, tres objetivos de produc-

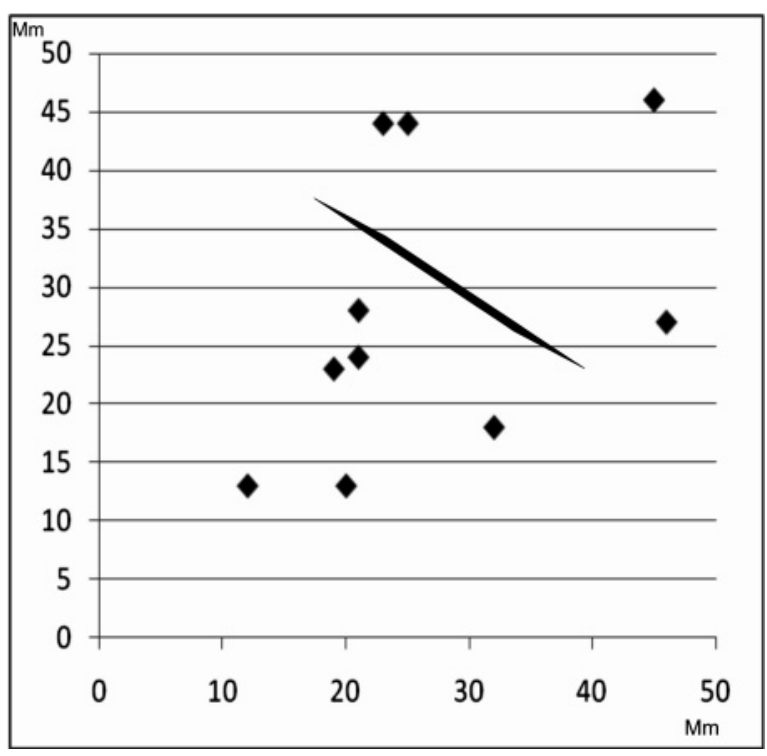

Fig. 3. Nivel 3, Paleolítico Medio, Cova Eirós (Triacastela, Lugo): relación longitud/anchura en los soportes completos (cuarcita y cuarzo) de producción unipolar. ción, con sus correspondientes organizaciones técnicas: lascas alargadas, productos de pequeño formato -con y sin preparación de plataformas- $y$ puntas.

La producción de lascas alargadas o laminares se ha reconocido a través de un único soporte de cuarcita completo $(61 \times 44 \times 10 \mathrm{~mm}$, Fig. $2: 1)$. Es una producción unipolar donde la plataforma ha sido convenientemente preparada, a través de facetado, para garantizar el control necesario para la obtención de los soportes. Dos negativos unipolares previos son objetivo de la producción y tres acondicionan la cara de lascado. Los elementos de producción Levallois centrípeta recurrente son dos lascas fracturadas de cuarcita $(39 \times 43 \times 8$ $\mathrm{mm}$ y $37 \times 36 \times 9 \mathrm{~mm})$. La producción microlevallois, ya evidenciada por un núcleo de cuarzo, se puede constatar también en dos lascas de cuarzo, de menos de $2 \mathrm{~cm}$ de longitud, con preparación de la plataforma de lascado y extracciones previas que muestran una explotación de tipo centrípeto recurrente. Por último, se ha desarrollado una producción Levallois recurrente unipolar, orientada a la obtención de puntas. Hay dos de cuarzo con fractura distal y una de cuarcita. Se estima que la longitud inicial estaría entre los 3 y $3,5 \mathrm{~cm}$. Este tipo de producción exige una detallada preparación de la cara de lascado y de la plataforma de golpeo.

Estas cuatro modalidades de explotación Levallois son independientes. La de producción de puntas es tan específica y estandarizada que es difícil de comprender en un programa de producción abierto donde se puedan generar varios formatos de soportes. La continuidad entre el unipolar y el centrípeto recurrente también es improbable porque un cambio de estrategia en el mismo núcleo implicaría una reducción sustancial de los soportes que no parece evidente en función de su tipometría.

La producción discoide, únicamente asociada a la cuarcita $(n=2)$, carece de plataformas corticales (talones lisos o diedros) pero al menos la pieza con restos de córtex en el lateral muestra que la explotación no está muy avanzada. Se buscan productos de tamaño medio (entre 4 y 4,5 $\mathrm{cm})$ y sección cuadrangular.

La producción Kombewa está presente en cuarzo y cuarcita, aunque en proporciones muy reducidas $(n=2)$. En cuarcita muestra una cuidada preparación de las plataformas (con facetado de los talones), a pesar de que el producto es de 
pequeño formato $(18 \times 26 \times 7 \mathrm{~mm})$. En este nivel, los objetivos de la producción Kombewa son muy similares a los buscados a partir de la producción microlevallois.

La producción Quina aparece en dos soportes completos $(36 \times 23 \times 18 \mathrm{~mm}$ y $25 \times 27 \times 11 \mathrm{~mm})$ con talones liso à pan y diedro asimétrico, respectivamente, y evidencias de cambio de los ejes de talla. No es muy frecuente que se obtengan soportes tan pequeños y sin dorsos corticales en este tipo de producción. Habitualmente, se buscan lascas de tamaño medio-grande -extraídas en series-, bastante espesas con secciones asimétricas y que capten flancos que funcionan como dorsos. Una está retocada como raedera lateral, aunque sin retoque escamoso-escaleriforme.

Hay tres soportes más de cuarzo con negativos previos de tipo bipolar. Uno conserva un talón machacado. Otro se ha extraído a partir de un plano de fractura. El último está fracturado por la zona proximal. Estas evidencias sugieren una explotación bipolar sobre yunque, habitualmente asociada a la talla de cuarzo. En la colección hay dos elementos más con talones machacados y negativos previos bipolares que pudieron haberse extraído a partir de una talla de este tipo.

\section{LA GESTIÓN DE LA PRODUCCIÓN}

Los soportes que proceden de explotaciones predeterminadas, además de diferencias técnicas, se individualizan por la materia prima, los rasgos morfotécnicos y el tipo de aprovechamiento.

Hay una gestión diferencial de la cuarcita y el cuarzo, manifestada en 1) el estadio en el que son aportadas al yacimiento, 2) el tamaño de los productos, 3) las estrategias de producción a las que se asocian o 4) el grado de modificación por retoque de los soportes.

En general, se aprecia un transporte de soportes finales en ambas materias primas y una producción de cuarzo in situ relacionada con un posible aprovisionamiento parcial en las inmediaciones de la cueva (ladera o río). Esta idea se sustenta, básicamente, en los cuatro núcleos asociados a la obtención de soportes de pequeño tamaño y en los seis soportes de inicio de explotación o apertura de cara de lascado. Su cara dorsal es totalmente cortical y la mayoría tienen entre 2 y $3 \mathrm{~cm}$.

La importación de soportes finales estaría relacionada con su tamaño. Como muestra la Figura 3, en el esquema unipolar se dan dos produc- ciones: una de soportes inferiores a $3 \mathrm{~cm}$ llevada a cabo in situ, algunos de los cuales se van a retocar (un raspador y una lasca retocada); y otra de soportes superiores a $4 \mathrm{~cm}$ ) que se importan al yacimiento como productos finales, retocados en cuarzo o en bruto para la cuarcita.

El 96\% de los soportes retocados son de cuarzo. Parece seleccionarse para retoque los productos de mayor formato. En términos absolutos las diferencias en el tamaño no son demasiado significativas $(30,3 \mathrm{~mm}$ de media en los retocados y $24,5 \mathrm{~mm}$ en los brutos) aunque hay que considerar la pérdida de masa que sufren en los procesos de conformación.

El grupo de retocados constituye casi el 20\% del total de la colección. Salvo una raedera sobre una lasca Quina, el resto son soportes de producción unipolar $(28 \%)$ o de esquemas no específi$\cos (68 \%)$.

Una parte importante de la gestión de la cuarcita tiene que ver con la obtención de unos soportes específicos/predeterminados, poco espesos y con filos brutos largos, que no se suelen retocar y que llegan al yacimiento como productos finales. Ello concuerda con las características de la producción discoide y Levallois y con el hecho de que el $95 \%$ de los soportes retocados sean de cuarzo. Una lasca de reavivado y otra de tipo Kombewa indicarían que esta materia prima también se habría utilizado para producir soportes posteriormente retocados/reavivados y lascas para su explotación como matrices. Todo esto pone de manifiesto que la gestión de la cuarcita es más compleja de lo que parece a simple vista y que se asocia a explotaciones intensivas.

La producción Quina (representada en dos piezas) se asocia únicamente al cuarzo. Este tipo de soportes, en general, están concebidos para ser retocados y empleados, probablemente, en ciclos de uso muy largos que incluirían un reavivado reiterativo de los filos (Bourguignon 2001). No obstante solo una de las dos está retocada.

A modo de conclusión, en la gestión del utillaje lítico del nivel 3 de Cova Eirós hay dos conjuntos diferenciados: una producción in situ en cuarzo de soportes de pequeño formato y otra de soportes importados obtenida con sistemas de talla predeterminados (Moncel et al. 2008) entre los que se incluyen casi todas las cuarcitas y una buena parte de los cuarzos (Duran y Soler 2006). No responde a un modelo de gestión diferencial de las materias primas por su aptitud para la talla o para el uso: 
hay puntas de proyectil o productos Levallois, Quina y Kombewa en cuarzo y en cuarcita. Lo que se da es una gestión diferencial según los sistemas de talla, con una especialización de la cuarcita pero una producción diversificada para el cuarzo. La producción de lascas de pequeño formato, obtenidas con técnicas variadas (unipolares, Levallois, Kombewa) abunda en una estrategia cada vez mejor documentada en el Paleolítico Medio, al menos desde el estadio isotópico 5 (Moncel 2003; González Urquijo et al. 2005; Dibble y McPherron 2006; Delagnes et al. 2007), asociada a menudo a producciones in situ (Moles y Boutié 2009).

Como balance, destaca la importancia de los productos Levallois y la escasez de los discoidales, en contra de lo esperable para conjuntos basados en cuarzo (Fábregas et al. 2007; Fábregas et al. 2008). En general se ha llevado a cabo una exhaustiva preparación de la plataforma de percusión -a través de facetado- y de la cara de lascado -con negativos centrípetos perimetrales para acentuar las convexidades. Los datos cuantitativos y las características tecnomorfológicas revelan una producción de puntas Levallois altamente sistematizada, con soportes de dimensiones estandarizadas (anchuras entre 25 y $28 \mathrm{~mm}$, espesores de $8 \mathrm{~mm}$ y longitudes estimadas, por las fracturas apicales, entre 30 y $35 \mathrm{~mm}$ ), talladas en cuarzo y cuarcita.

\section{LA FUNCIÓN DEL UTILLAJE}

\subsection{Planteamientos metodológicos y objetivos}

Una de las cuestiones más importantes que definen el interés de los estudios funcionales es que completa la comprensión de las opciones técnicas tomadas en los procesos de producción y gestión del utillaje. Además, nos remiten a otros procesos de producción y gestión en materias perecederas, como la piel o madera, sobre las que de otra forma solo podríamos conjeturar. Este conjunto de informaciones nos acerca a los comportamientos económicos generales relativos a la funcionalidad de los asentamientos, la gestión del territorio o la captación de recursos.

En este marco, los objetivos principales del estudio funcional del nivel 3 de Cova Eirós son 4: a) comprobar las posibilidades de observación microscópica para estos contextos y en materias como la cuarcita y el cuarzo, b) conocer algunas de las actividades realizadas en el yacimiento, c) comprender mejor la función del asentamiento y d) estimar el grado de complejidad y de planificación de los comportamientos económicos, en el marco de la discusión sobre las formas de organización de las sociedades neandertales.

Un estudio funcional con máximas garantías requiere establecer un marco comparativo a través de un programa experimental (generado en unas condiciones controladas), en el que reconocer y caracterizar las huellas de uso. Para el del nivel 3 de Cova Eirós (observación e interpretación de T. Lazuén) se han utilizado dos programas experimentales: uno para la cuarcita (J. F. Gibaja e I. Clemente) y otro para la cuarcita y cuarzo (T. Lazuén). El cuarzo se ha recogido en la zona de la cueva, con el objeto de aumentar al máximo las similitudes entre la colección comparativa y la arqueológica. Estos programas experimentales acogen más de 300 actividades que combinan diversas tareas, materias trabajadas y tiempos de trabajo, incluyendo la reproducción del uso de proyectiles de cuarzo y cuarcita.

El estudio funcional sobre cuarcitas o cuarzos no es exactamente una novedad, pero sigue siendo escaso, más aún si tratamos de contextos cronológicos antiguos: el de S. Beyries y H. Roche (1982) en los Carrières Thomas, C. Sussman (1987, 1988) en Olduvai, R. K. Pant (1989) en l'Aragó, E. Carbonell et al. (1999) en TD6 de Atapuerca, B. Márquez et al. (1999) en Trinchera Galería, y B. Márquez y J. Baena (2002) en El Esquilleu. Para períodos antiguos hay más trabajos orientados a conocer la función del instrumental tallado en sílex: L. H. Keeley (1980), J. J. Shea (1988, 2006), H. Plisson y S. Beyries (1999), A. Ollé et al. (1999), J. M. Vergés et al. (1999), C. Lemorini (2000), K. Martínez et al. (2005), P. Villa et al. (2009).

Para conjuntos con otras materias primas y períodos más recientes, destacan por sus importantes aportes metodológicos los trabajos de H. Plisson(3), I. Clemente y J. Gibaja (2009) o Gibaja y Clemente (2009).

El hecho de que las características litológicas de estas dos rocas sean muy diferentes a las del sílex obviamente afecta a la percepción de las

(3) Plisson, H. 1985: Étude fonctionnelle d'outillages lithiques préhistoriques par l'analyse des micro-usures: recherche méthodologique et archéologique. Tesis doctoral, Université de Paris I. 
huellas de uso a nivel microscópico. La cuarcita es una roca metamórfica compuesta por cristales de cuarzo, unidos entre sí por un cemento (matriz) fundamentalmente cuarzoso aunque, en ocasiones, y según el tipo, aparecen minerales accesorios como mica, feldespatos, granitos, etc. Provienen de la recristalización de las areniscas, por lo que son más duras y resistentes a las agresiones. El cuarzo está compuesto por sílice. Es cristalino en estado puro y puede adquirir distintas tonalidades en función de las impurezas que contenga. Casi no presenta exfoliación y sus cristales no están cementados. Los cristales en el cuarzo hialino y en la cuarcita son extremadamente duros y resistentes -más que el sílex o cualquier otra roca empleada en la Prehistoria como utillaje tallado (Huet 2006)- pero sus cualidades para la talla y para el uso dependen precisamente de las uniones entre los cristales. La variabilidad es muy alta, pero algunos bloques de cuarcita y cuarzo de buena calidad proporcionan filos tan cortantes y eficaces como las mejores rocas.

La dificultad mayor en el análisis funcional de las cuarcitas está en la heterogeneidad de la textura y composición de la roca, formada por cemento y cristales. A escala microtopográfica cada cristal se comporta de forma autónoma, en función de su orientación y posición por una parte, $\mathrm{y}$ de su distancia y relación con la zona activa, por otra. Los cristales pueden sufrir corrosiones, estriaciones, desconchamientos y fracturas. El cemento de la matriz suele resultar más blando que los cristales y registra unas alteraciones diferentes, en las que priman el redondeamiento $\mathrm{y}$, en algunos casos, los pulidos. Las huellas en cuarzo son bastante similares a las que se encuentran en los cristales de las cuarcitas o en rocas cristalinas como la obsidiana. A pesar de las dudas de los años 1980 sobre las posibilidades de los análisis funcionales en cuarzo (Sussman 1985), el registro y la conservación de las huellas en esta materia prima parecen comparativamente mejores que en la cuarcita.

La determinación de las huellas de uso en rocas diferentes al sílex también se discute. Según algunos autores los estudios funcionales de cuarcitas están poco desarrollados y, además, son bastante superficiales y tienden a utilizar modelos de huellas conocidos experimentalmente para el sílex (Gibaja et al. 2002). Otros consideran que en un análisis traceológico estas materias primas suponen, en sí mismas, un condicionante negativo (Márquez y Baena 2002). La lectura y documentación de las huellas de uso en cuarzo y, sobre todo, en cuarcita son muy complejas. En el estado actual de la investigación, la confianza en su determinación es más baja que en el sílex, por la ausencia de trabajos que reglen los patrones de uso asociados a las materias trabajadas. Hasta ahora, el pulido desarrollado en sílex es el mejor tipo de evidencia para hacer estas determinaciones, gracias a su sistematización desde hace más de dos décadas(4) (González Urquijo e Ibáñez 1994). Sin embargo, al no ser extrapolable a otros tipos de rocas algunas asociaciones tienden a ser algo más tentativas. La conservación de las huellas es una ventaja cualitativa de estas materias primas sobre el sílex en el estudio funcional. El sílex parece más frágil, sobre todo frente a las alteraciones químicas que provocan disoluciones más marcadas en las superficies, algo especialmente manifiesto en los conjuntos antiguos. Respecto al estado de conservación y las posibilidades de observación de la muestra analizada hemos advertido cierta alteración debida al "lustre del suelo" que resultaría de acciones químicas o mecánicas dentro del propio sedimento (Levi-Sala 1996). En el sílex esta alteración se manifiesta como un pulido característico que comienza por las aristas, filos y zonas elevadas de la microtopografía, y lo hace indiferenciable de los micropulidos poco desarrollados generados por el trabajo sobre materias blandas. Parece que los suelos ácidos favorecen la aparición de este tipo de alteración (Plisson y Mauger 1988; Lemorini 2000). En rocas como el cuarzo o la cuarcita, con características de estructura y composición diferentes, este fenómeno se manifiesta básicamente en la aparición de estrías con orientaciones desordenadas, longitudes y anchuras muy variables y algunas otras figuras de corrosión en la superficie de los cristales. No obstante, el conjunto seleccionado presenta un bajo impacto de estas alteraciones, que han sido diferenciadas de las propias del uso por sus características y su situación.

En base a los objetivos generales del estudio hemos seleccionado una muestra de 19 piezas compuesta por lo que presumíamos como productos finales, ya sean útiles retocados o piezas procedentes de producciones específicas. Hemos desechado el material con alteraciones macros-

(4) Véase n. 3. 
cópicas y los restos de talla. De las 19 piezas seleccionadas, 11 presentan huellas de uso. La observación de las piezas ha combinado un estereomicroscopio o una lupa binocular (Leica S8APO), con dispositivo zoom hasta 80 aumentos, y dos microscopios metalográficos (Leica DM 2500M y Leica DMLM), entre 50X a 500X, del Instituto de Prehistoria (IIIPC) de la Universidad de Cantabria. Tras comprobar la ausencia de residuos asociados al uso o enmangue, se limpiaron los materiales, para eliminar adherencias postdeposicionales que pudiesen ocultar o falsear las trazas de uso. Utilizamos agua y jabón y en algunos casos alcohol impregnado en un bastoncillo de algodón. Para garantizar la conservación del material se ha evitado el uso de ácidos y bases. En algunas macrofotografías con lupa binocular, especialmente de las puntas y de las piezas astilladas, se ha empleado humo de magnesio con el fin de limitar los brillos característicos de este tipo de rocas.

\subsection{Resultados de la observación}

Los soportes se emplearon en el trabajo de piel seca, madera, carnicería y para cazar.

Hay cuatro soportes empleados en el trabajo de piel seca:

1) Raedera lateral conformada sobre un soporte de cuarzo de producción unipolar, con un retoque alternante en el lateral derecho. Mide $44 \times 25 \times 11 \mathrm{~mm}$ y está completa. El filo activo, de $43 \mathrm{~mm}$ de longitud, presenta una delineación ligeramente sinuosa y un ángulo abrupto entre $80^{\circ}$ y $90^{\circ}$. Su uso ha generado un patrón de huellas netamente diferenciadas en la cara ventral y en la dorsal del filo activo. En la ventral, en los primeros momentos del trabajo se han producido algunos desconchados de pequeño tamaño (entre 50 y $100 \mu \mathrm{m})$ que, debido a la intensidad del trabajo y/o a lo abrasivo de la materia trabajada, han sido borrados en parte por el redondeamiento que ha producido el trabajo posterior. En los bordes de los cristales más cercanos al filo estricto se observan estrías abundantes que invaden el interior de la pieza hasta $0,3-0,4 \mathrm{~mm}$. Su dirección es fundamentalmente transversal, aunque aparecen algunas paralelas al filo (Fig. 4: A y B). En la cara opuesta se acumulan desconchados de tamaño medio-grande, sin estrías ni redondeamiento. Este conjunto de rastros describe un patrón típico de raspado en un solo sentido, donde la cara ventral sería la cara activa y de contacto. El conjunto de huellas permite reconocer el trabajo sobre una materia muy abrasiva que hemos interpretado como piel seca. La existencia de algunas estrías longitudinales indica que, en algún momento del procesado (probablemente al comienzo, cuando el filo está más vivo), se ha realizado algún trabajo puntual de corte, presumiblemente sobre la misma piel.

2) Raspador de cuarzo fabricado sobre un soporte de $22 \times 21 \times 6 \mathrm{~mm}$, con un frente activo de $14 \mathrm{~mm}$ de longitud y un ángulo entre $75^{\circ}$ y $80^{\circ}$. Como en el denticulado anterior, este instrumento ha sufrido una fase de reavivado importante. Sin embargo, conserva restos del filo fósil con huellas de uso bastante intensas: un claro redondeamiento y embotamiento del filo original, con límites netos con las zonas reavivadas. Este rejuvenecimiento del filo se evidencia tanto en el aspecto fresco del cristal como en las líneas de fractura concoide latentes, consecuencia de una percusión que no ha llegado a desprender la materia. Dichas líneas diferencian la zona de filo estricto, machacada y con algunos microdesconchados (de entre 50 y $100 \mu \mathrm{m}$ ), y la que se encuentra un poco más hacia el interior de la pieza, algo estriada y resquebrajada pero sin ese grado de alteración (Fig. 4: C y D). Este patrón de huellas evidencia un trabajo transversal sobre una materia muy abrasiva, que hemos determinado como raspado de piel seca.

3) Lasca de cuarcita, de gran formato $(61 \times 44 \times 10 \mathrm{~mm})$, fabricada mediante producción Levallois unipolar. Las huellas de uso se localizan en la zona distal, con un frente de delineación convexa de $32 \mathrm{~mm}$ y ángulo entre $45^{\circ}$ y $50^{\circ}$. La zona activa está intensamente redondeada con huellas muy diferentes en las dos caras. En la ventral, los cristales que se conservan presentan corrosión, fracturas y estrías profundas y una distribución gradual en función de la cercanía al filo estricto (Fig. 5). En la dorsal (pasiva) se han generado desconchados de formato medio-grande, sin evidencias de estrías, corrosiones o redondeamiento. Este conjunto de rastros describe un patrón típico de raspado en un solo sentido, siendo la cara ventral la activa y de contacto. Permite reconocer el trabajo sobre una materia muy abrasiva que hemos interpretado como piel seca. Una fractura, en la parte proximal del soporte, tiene aspecto de conformación específica para 

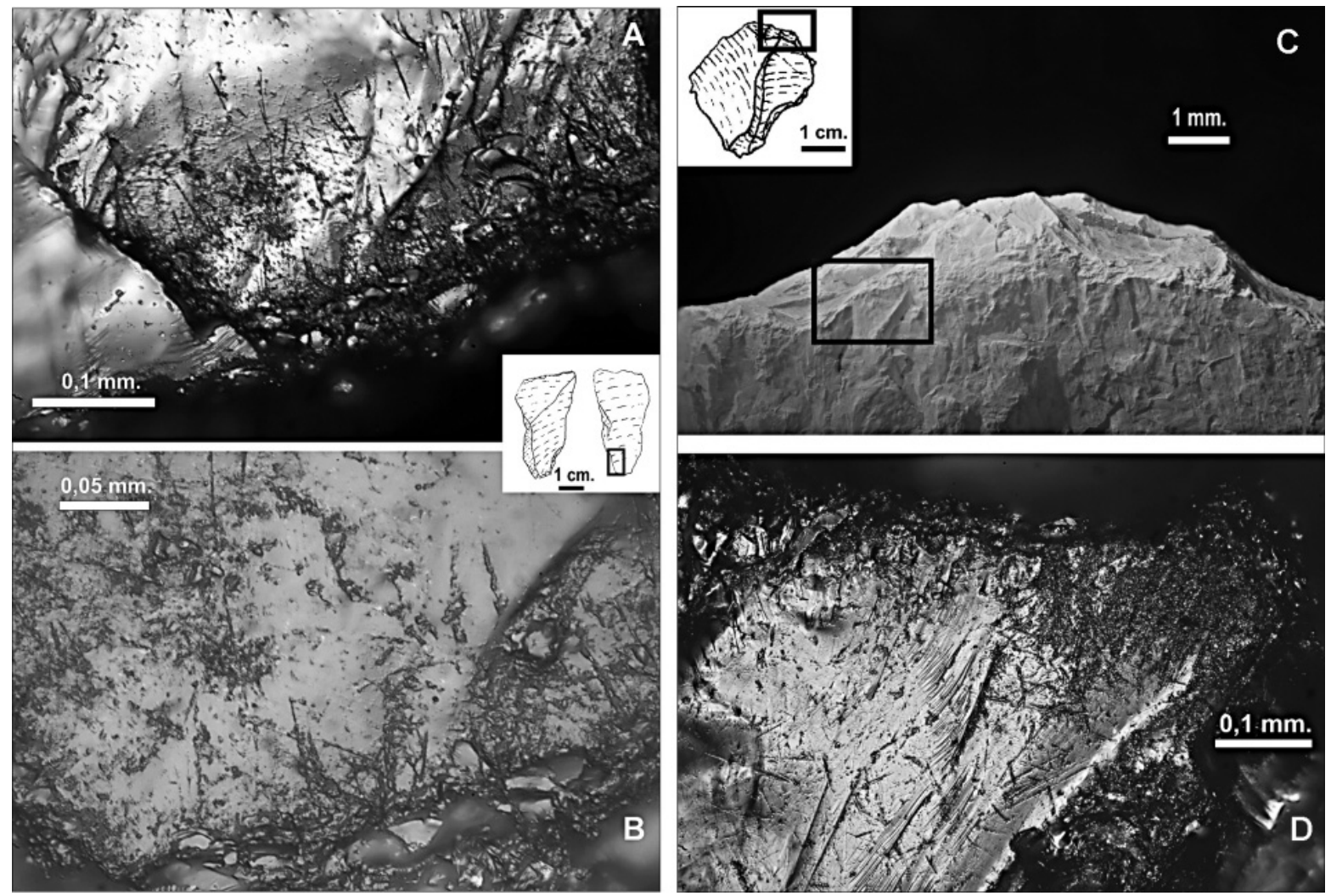

Fig. 4. Nivel 3, Paleolítico Medio, Cova Eirós (Triacastela, Lugo). Huellas de raspado de piel seca: A. microscopio metalográfico 200X, B. microscopio metalográfico 500X, C. estereomicroscopio 10X, D. microscopio metalográfico 200X. Foto T. Lazuén.

enmangue. Estas adaptaciones se conocen en otros conjuntos del Paleolítico Medio, donde se han documentado huellas producidas por enman-

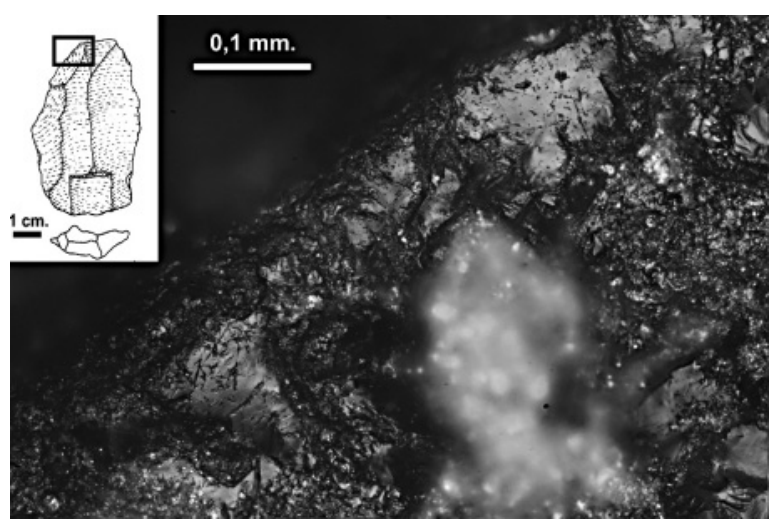

Fig. 5. Nivel 3, Paleolítico Medio, Cova Eirós (Triacastela, Lugo). Huellas de raspado de piel seca (microscopio metalográfico 200X). Foto T. Lazuén. gue (Márquez y Baena 2002; Carrión y Baena 2003).

4) Útil doble formado por una pieza astillada con un filo lateral denticulado, sobre soporte de cuarzo de producción unipolar $(44 \times 23 \times 8 \mathrm{~mm})$. El filo denticulado mide $23 \mathrm{~mm}$ de longitud. La pieza ha sufrido un proceso de reavivado que concentra las principales evidencias de uso en los restos del filo fósil, donde se aprecia un alto grado de redondeamiento. El cristal se ha abrasionado en las zonas más cercanas al filo. Hacia el interior, donde está mejor conservado, se agrupan estrías profundas y otras más superficiales (Fig. 6: B y C). El rejuvenecimiento de la zona activa se deduce del estado del cristal y de las líneas de fractura concoide latentes, en zonas percutidas pero que no han terminado de desprenderse. Posiblemente el filo previo, sobre el que se registran las huellas de uso, no sería denticulado -difícil de comprender para el trabajo sobre piel seca. Desconocemos su delineación concreta pero 

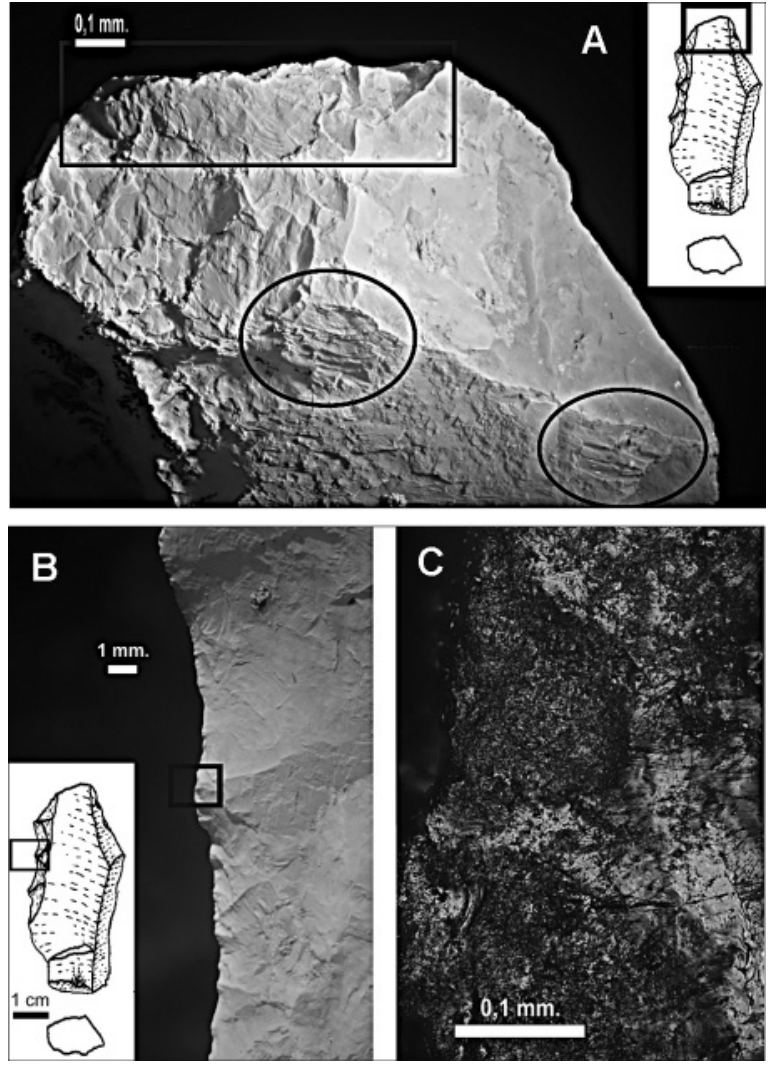

Fig. 6. Nivel 3, Paleolítico Medio, Cova Eirós (Triacastela, Lugo). Huellas del trabajo de percusión en la parte distal: A. estereomicroscopio 11X. Huellas fósiles previas al retoque denticulado: B. estereomicroscopio $12 \mathrm{X}$, C. microscopio metalográfico 200X. Foto T. Lazuén.

es probable que fuera recto. El denticulado resultaría de una fase de reciclado del útil para desempeñar una función que, o bien no se llegó a realizar, o no generó rastros visibles. Las huellas evidencian un trabajo en sentido transversal sobre una materia bastante abrasiva, que hemos asociado con el raspado de piel seca. Los desconchados bifaciales asimétricos en los dos extremos del útil astillado indican una percusión oblicua (Fig. 6: A). En la colección hay cuatro piezas de cuarzo, con el mismo tipo de alteraciones en los extremos del soporte. Este patrón de huellas apunta al uso de la pieza como cincel, cuña o pieza intermediaria. Nos remite a un trabajo sobre una materia semidura o dura, madera o tejidos óseos, para henderlas por percusión indirecta. Discriminar ambas categorías es complicado cuando se trata de percusión (González Urquijo e Ibáñez 1994). En estas tareas, la mayoría de las huellas generadas son desconchados o esquirlamientos. Hay poca fricción entre la materia trabajada y las superficies activas de los útiles por lo que no aparecen o no se conservan las zonas abrasionadas, estriadas o pulidas que suelen proporcionar las mejores evidencias diagnósticas sobre la materia trabajada. El uso de cuñas puede relacionarse, excepcionalmente, con el acceso a la médula del hueso pero en general se asocia a trabajos más complejos que requieren precisión en la fractura porque los fragmentos (hueso o asta) se emplean como soporte para la fabricación de útiles(5). Dado que estas labores no parecen propias del contexto que estudiamos, probablemente abrirían vástagos de madera de unos pocos centímetros de diámetro. E1 tamaño y la terminación de los desconchados sugieren también un contacto poco traumático, con una materia semidura.

Hay un soporte asociado a un trabajo sobre madera: una raedera lateral fabricada sobre una lasca de producción Quina en cuarzo $(36 \times 23 \times 18$ $\mathrm{mm})$. La longitud del filo útil es de $31 \mathrm{~mm}$ con una delineación suavemente denticulada; el ángulo activo es robusto, en torno a $90^{\circ}$. El patrón de huellas de desgaste es bastante complejo. La arista del filo presenta numerosos desconchados de morfologías irregulares y terminaciones abruptas. Se aprecian fracturas de los cristales, en cuyos bordes se han generado, en ocasiones, microdesconchados transversales de unas pocas decenas de micras de dimensión máxima. En las zonas más cercanas al filo se concentran componentes lineales - estrías de fondo oscuro y corrosiones orientadas- que muestran una dirección transversal, aunque ligeramente oblicua, respecto al filo (Fig. 7: A). Sugieren el raspado sobre una materia semidura, probablemente madera. En algunas zonas del filo, parte de las huellas han sido eliminadas por extracciones de mayor tamaño que modifican su distribución original. Estas extracciones reflejan un reavivado parcial del filo que, como vemos, provoca una fuerte alteración de las cualidades mordientes del filo original.

Hay un soporte empleado en el trabajo de carnicería, una lasca bruta de cuarcita de producción discoide $(42 \times 54 \times 10 \mathrm{~mm})$. El filo activo mide $40 \mathrm{~mm}$ de longitud y un ángulo entre $30^{\circ} \mathrm{y}$ $35^{\circ}$. Presenta algunos microdesconchados (de no

(5) Múgica, J. A. 1991: La industria ósea del Paleolítico Superior y Epipaleolítico del Pirineo Occidental. Tesis doctoral, Universidad de Deusto, Bilbao. 
más de $50 \mu \mathrm{m}$ ), resquebrajamientos y microfracturas de los cristales en el borde del filo, así como algunas estrías aisladas orientadas en sentido longitudinal (Fig. 7: B) a todo lo largo del filo pero de forma bastante dispersa. Este patrón, con cristales poco alterados pero con huellas traumáticas de percusión, alternadas con algunas estrías, caracteriza la carnicería primaria. En este procesado, el contacto con la carne no es sencillo de determinar, porque genera rastros poco desarrollados y definitorios fácilmente enmascarables con la mínima alteración. Pero durante el contacto esporádico con las partes esqueléticas del animal se forman huellas más claras. Un examen tafonómico preliminar de los restos de macrofauna (Fábregas et al. 2010) ha apreciado marcas de corte en algunos huesos de ungulados. Es habitual la asociación de estas tareas a soportes sin retocar con filos más o menos agudos (Lemorini 2000; Gibaja 2007).
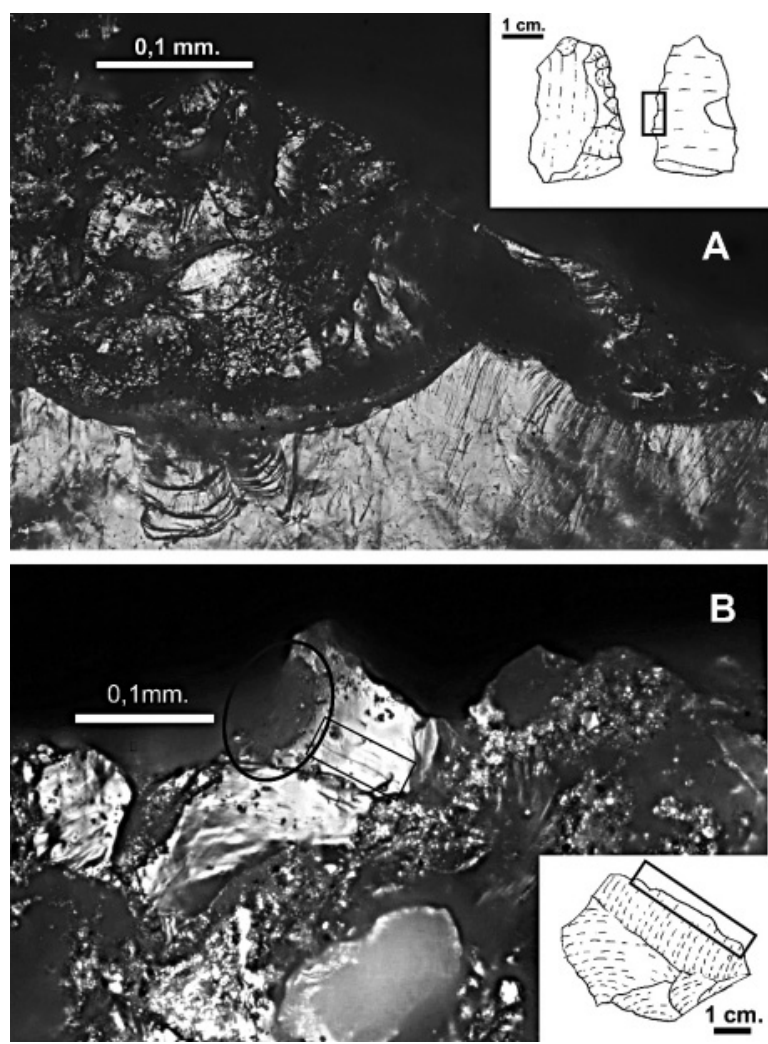

Fig. 7. Nivel 3, Paleolítico Medio, Cova Eirós (Triacastela, Lugo). A. huellas de raspado de madera (microscopio metalográfico 200X), B. huellas de carnicería (microscopio metalográfico 200X). Foto T. Lazuén.
En el nivel 3 de Cova Eirós hay cinco puntas de proyectil: dos prácticamente completas, una fracturada y dos ápices. Se han fabricado con cuarzo $(n=4)$ y cuarcita $(n=1)$. No se ha podido determinar el esquema de fabricación de los ápices; las otras proceden de una producción de tipo Levallois recurrente unipolar específica para la obtención de puntas.

1: de cuarzo $(25 \times 25 \times 8 \mathrm{~mm})$. Le falta el ápice. La arista distal está algo desviada del eje tecnológico y, por tanto, la punta entera también debería estarlo. Conserva como huellas de uso una fractura con negativo en lengüeta que ha suprimido el tercio distal. Ha generado rebabas hacia ambas caras, en especial hacia la dorsal (Fig. 8: B). La fractura se ha retocado (Fig. 8: A), creando un filo convexo, para utilizar el soporte en una actividad que no ha podido ser determinada.

2: de cuarzo $(29 \times 28 \times 8 \mathrm{~mm})$. Está fracturada en la zona distal y proximal. En la distal tiene tres fracturas escalonadas y rebabas hacia la cara ventral a lo largo de más de 0,5 cm (Fig. 8: C). La fractura proximal se debe a un contacto brusco contra el astil por el impacto.

3: de cuarcita, completa $(28 \times 26 \times 8 \mathrm{~mm})$. Presenta desconchados hacia la cara ventral de 3-4 $\mathrm{mm}$ de longitud con terminación afinada (Fig. 8: D y E). Su determinación como huella de impacto es menos concluyente debido a que desconchados de este tamaño, morfología y terminación pueden generarse por otros tipos de alteraciones.

4: ápice $(15 \times 8 \times 5 \mathrm{~mm})$, de cuarzo. Representa el positivo de una fractura burinante por impacto y muestra otra burinante de terminación abruptareflejada de unos $8 \mathrm{~mm}$ de longitud (Fig. 8: F).

5: ápice $(16 \times 11 \times 6 \mathrm{~mm})$ roto por un plano de fractura del cuarzo, en algún momento traumático como el contacto con la presa o la recuperación del vástago. Tiene además desconchados de impacto en la zona distal, hacia las dos caras (Fig. 9). Hacia la dorsal un largo desconchado escalonado de más de $1 \mathrm{~cm}$ siguiendo una arista de la cara dorsal. Hacia la ventral hay otro ancho y plano de unos $7 \mathrm{~mm}$.

Las características técnicas y morfológicas de estas puntas muestran claros rasgos de estandarización en la fabricación. Todas miden entre 30 y $35 \mathrm{~mm}$ de longitud y 25 y $28 \mathrm{~mm}$ de anchura y $8 \mathrm{~mm}$ en sección. Dos de las tres más completas presentan, en el lateral mesoproximal del filo, una muesca que modifica su delineación original predeterminada para crear un entrante cóncavo. Esta 

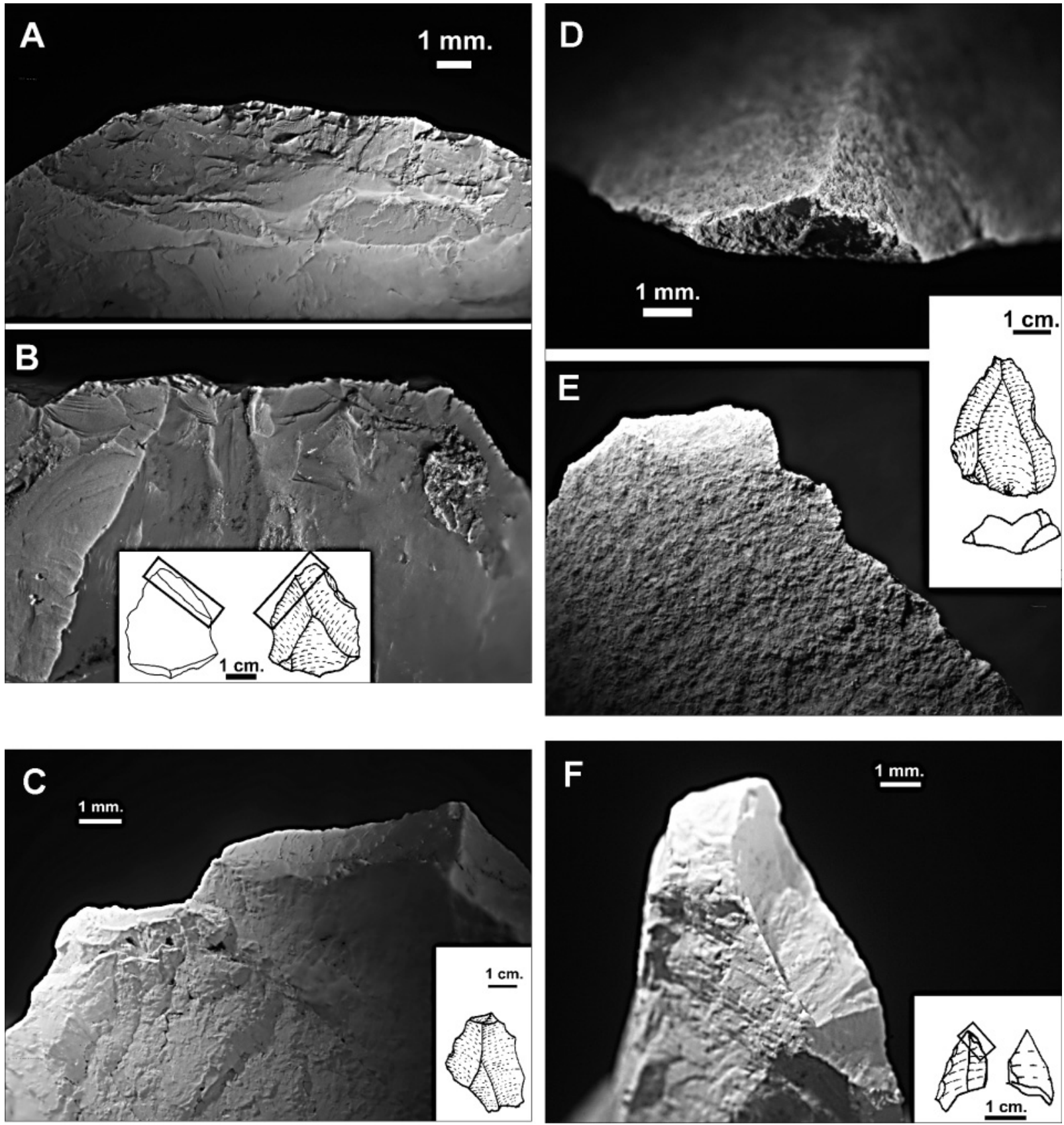

Fig. 8. Nivel 3, Paleolítico Medio, Cova Eirós (Triacastela, Lugo). Huellas de impacto en puntas Levallois de cuarzo $(\mathrm{A}-\mathrm{C}, \mathrm{F})$ y cuarcita (D, E): A. fractura retocada (estereomicroscopio 9X), B. rebabas hacia la cara dorsal (estereomicroscopio 6,5X), C. fractura triple con rebabas hacia la cara ventral (estereomicroscopio 10X), D-E desconchados hacia la cara ventral: D. vista apical (estereomicroscopio 12,5X), E. vista desde la cara ventral (estereomicroscopio 6X), F. ápice, fractura burinante de terminación abrupta (estereomicroscopio 10X). Foto T. Lazuén.

muesca puede estar relacionada con algunas modalidades de enmangue como las que sugiere J. J. Shea (1989) para las puntas Levallois de Kebara, Hayonim y Qafzeh, cuya parte proximal estaría asegurada al astil -para evitar torsiones- mediante tiras de fibras vegetales o tendones. Este acondicionamiento específico, con muescas en las zonas proximales, también se ha sugerido como

Trab. Prehist., 68, N. ${ }^{\circ}$ 2, julio-diciembre 2011, pp. 237-258, ISSN: 0082-5638 doi: $10.3989 /$ tp.2011.11068 


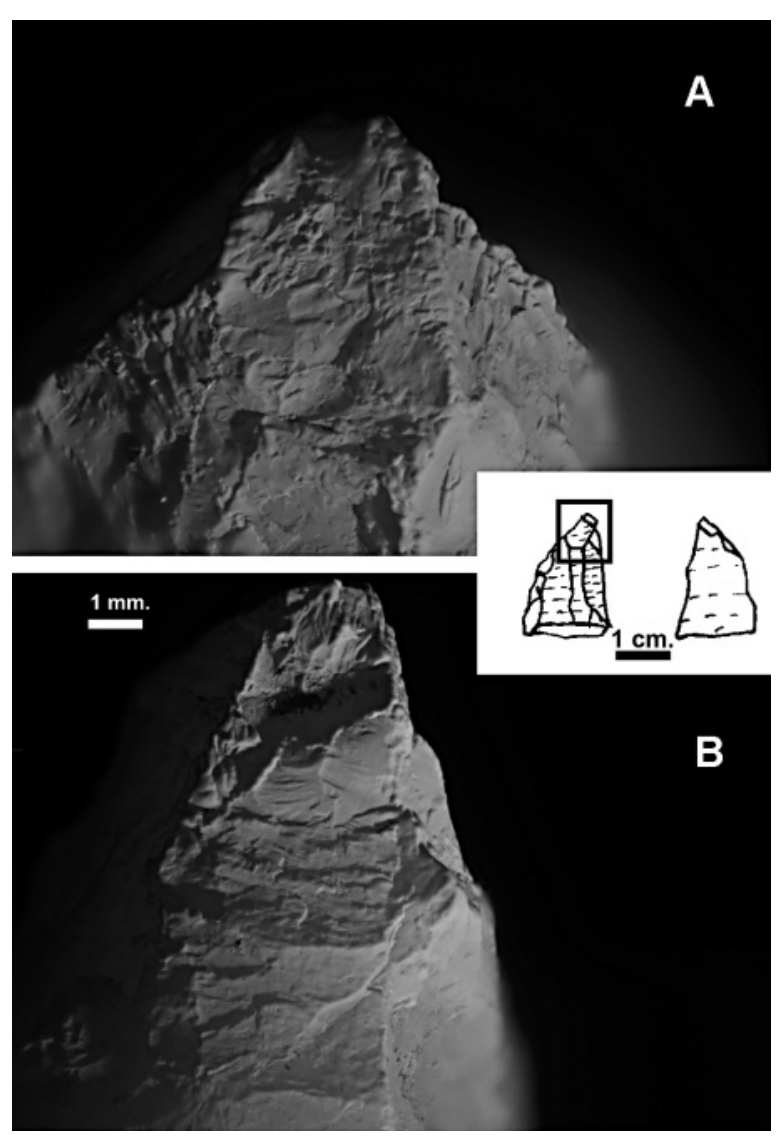

Fig. 9. Nivel 3, Paleolítico Medio, Cova Eirós (Triacastela, Lugo). Ápice de punta de cuarzo, desconchados: A. plano hacia la cara ventral (estereomicroscopio 9X), B. escalonado de terminación abrupta hacia la dorsal, (estereomicroscopio 12X). Foto T. Lazuén.

una preparación para el enmangue de las puntas Levallois en Umm-el-Tlel (Boëda et al. 1998, Fig. 14). Todas las puntas presentan huellas de impactos más o menos severos. De hecho, los dos ápices reconocidos son en sí mismos los positivos de las fracturas de impacto sufridas por sendas puntas. La significatividad de este tipo de fracturas está ampliamente contrastada por estudios experimentales (Bergman y Newcomer 1983; Fischer et al. 1984; Odell y Cowan 1986; Dockall 1997; Shea et al. 2002; Lombard et al. 2004). Las trazas de los elementos de proyectil son desconchados laterales burinantes y distales en lengüeta, fracturas en escalón, otras en el ápice con rebabas que indican la dirección del golpe o fracturas y desconchados proximales, consecuencia del contacto brusco contra el astil en el impacto. A ellas se añaden ocasionalmente las estrías de fondo plano u oscuro y los pulidos lineales. Estas huellas se distinguen claramente de las de pisoteo (trampling) o de las postdeposicionales (Prost 1987; Shea y Klenck 1993; McBrearty et al. 1998). Los estudios experimentales muestran de forma consistente que un porcentaje importante de las puntas no sufre alteraciones diagnósticas con un solo impacto. Necesitan ser reutilizadas en varias ocasiones para que se genere una huella de fatiga. Si no podemos documentar este tipo de rastros no podremos certificar que se trata de elementos de proyectil.

\subsection{La interpretación funcional en contexto}

El análisis funcional de la muestra del material lítico recuperado en el nivel 3 de Cova Eirós refleja el trabajo de una cierta variedad de materias en procesos técnicos elaborados, sobre todo actividades de caza y tratamientos de piel seca.

El trabajo de carnicería se relaciona con el primer procesado de la carcasa animal, donde el descuartizamiento o despiece obliga al contacto de los filos activos con partes más duras del esqueleto. No puede descartarse que el fileteado, la preparación de la carne o su consumo, que implican también el corte de carne, se hayan llevado a cabo en el yacimiento pero, como este tipo de huellas se generan y se conservan con dificultad, son especialmente difíciles de determinar, más aún en las materias primas en las que se ha fabricado el utillaje de Cova Eirós. La lasca bruta usada fue obtenida en una producción discoide. En ocasiones, la producción discoide del Paleolítico medio de la Península Ibérica, sobre todo para la obtención de puntas pseudolevallois, se ha vinculado precisamente a trabajos de carnicería primaria por sus características morfológicas $(\mathrm{Ca}-$ rrión et al. 2008; Ríos 2008). Estas asociaciones tenían hasta ahora un carácter especulativo al carecer de estudio funcional. En el caso del nivel 3 de Cova Eirós sí queda contrastada esta asociación al menos en un caso, aunque esto, obviamente, no descarta el uso de estos soportes sobre otro tipo de materias.

Cuatro piezas se han utilizado para raspar piel seca: una raedera, un denticulado y un raspador de cuarzo; la última es una lasca Levallois de cuarcita de producción unipolar y de formato grande. Hay una cierta alternancia de filos rectos - para la raedera y el filo previo al denticulado- y 
convexos -para el raspador y la lasca-. El trabajo de la piel es un proceso técnico de características bastante complejas (Lemorini 1999). Supone un despellejado cuidadoso de las presas abatidas, una limpieza con la piel aún fresca para evitar la putrefacción y una secuencia variable de tratamientos, que incluye raspados y cortes de la piel seca. Este procesado se vincula con una gestión asimismo compleja porque el secado introduce un lapso temporal importante y, a menudo, el transporte de las pieles hasta el lugar donde van a ser tratadas. La constatación de este proceso en la fase final, de afinado de la piel, no excluye que se haya trabajado sobre piel fresca. Como ocurre con la carnicería secundaria, ese raspado es bastante difícil de documentar. En general, deja en los instrumentos líticos unas huellas poco desarrolladas que pueden ser fácilmente enmascaradas por cualquier tipo de alteración. Por ello, que la actividad esté poco representada en las colecciones no es un dato concluyente sobre la ausencia de esta fase en el yacimiento. Como ya se ha advertido, las evidencias de trabajo de piel seca en un asentamiento nos remiten a tareas técnicamente complejas que suponen procesos de amplio alcance espacial y temporal, una importante inversión de esfuerzo, personal y utillaje y, en consecuencia, un alto grado de organización. Este tipo de procesos técnicos llevados a cabo en tiempos diferidos y que implican una modificación o transformación del estado de la materia son la prueba más clara del nivel de complejidad al que nos referimos.

Las cuatro piezas astilladas de la colección apuntan a un trabajo de percusión indirecta, probablemente asociada al uso de madera. Unidas a la raedera empleada para raspar madera, reflejan un procesado sumario de esta materia leñosa, quizás asociado a la fabricación de mangos y astiles para utillaje compuesto.

Tres de las cinco puntas de proyectil corresponden a soportes de producción Levallois específica para puntas. Sin embargo, este rasgo tecnomorfológico no permite deducir directamente la función de estos soportes. Piezas cuyas características morfológicas anuncian a priori elementos de proyectil y que, en otros contextos, han funcionado como tales, resultan haber sido usadas en actividades de carnicería, piel o madera. Es el caso de algunas puntas musterienses (Gibaja 2007) o Levallois (Plisson y Beyries 1999). Los dos elementos de proyectil restantes correspon- den al extremo apical de sendas puntas. Ya se ha explicado la vinculación del acondicionamiento en el lateral derecho de dos de las tres puntas Levallois para crear una concavidad con una conformación para enmangue. Esto, unido a la fabricación de soportes predeterminados, remite a un comportamiento estandarizado, tanto desde el punto de vista de la producción como del acondicionamiento de estos útiles para ser usados.

Los dos extremos distales fracturados (ápices) solo se explican si entraron en el yacimiento clavados en una presa (Plisson y Geneste 1989). Al no ser elementos reconfigurables, de otra forma, no tendrían sentido en el sitio. La existencia de utillaje de uso en carnicería primaria, que indicaría que parte del procesado inicial de recursos animales se llevarían a cabo en el yacimiento, avala también esta idea.

La propia presencia de elementos de proyectil plantea qué función cumple el yacimiento en las estrategias de explotación del territorio diseñadas por sus ocupantes. En contextos cronológicos cercanos al que estudiamos, la baja proporción de puntas con fracturas de impacto se vincula con sitios residenciales (Villa et al. 2009). Otras referencias arqueológicas y etnográficas sugieren lo contrario. Los restos de los proyectiles usados se concentrarían en los lugares residenciales o más estables porque las labores de reacondicionamiento del armamento de caza se producen más a menudo allí, donde se centralizan las actividades más complejas (Geneste y Plisson 1993; Ibáñez y González Urquijo 1996). En el nivel 3 de Cova Eirós llama la atención la alta proporción de elementos de proyectil con huellas de impacto. Ello sugiere una acumulación de elementos desechados, es decir, un lugar de reposición de las puntas de proyectil gastadas.

La identificación e interpretación funcional de las puntas del Paleolítico Medio se ha concentrado en Próximo Oriente, sur de África y también en Europa, siguiendo el trabajo de J. J. Shea con las puntas Levallois (Shea 1988, 1989, 1993, 2006; Shea et al. 2002; Plisson y Beyries 1999; Lombard 2005; Moncel et al. 2009; Villa y Lenoir 2009; Villa et al. 2009) y analizan aspectos morfotécnicos, fracturas de impacto y residuos. Esta línea de investigación ha cobrado especial relevancia en el marco de la discusión en boga acerca de las capacidades cognitivas, e incluso físicas, de los neandertales. Los testimonios de armamento compuesto en el nivel 3 de Cova 
Eirós nos remiten ineludiblemente a ella. En la bibliografía científica ha sido recurrente la idea de que ni los sistemas técnicos, ni la organización social de los grupos neandertales estarían lo bastante desarrollados como para cazar de forma activa y sistemática. Sin embargo, las evidencias arqueológicas ponen de manifiesto su capacidad para cazar gran variedad de piezas, incluidos los animales de gran talla a los que habitualmente aparecen asociados (Callow y Cornford 1986; Gaudzinski 2000; Roebroeks 2001). La documentación de Cova Eirós que acabamos de presentar se suma a este creciente conjunto de referencias. Todas muestran que los grupos neandertales no eran carroñeros secundarios ni cazadores limitados. Para un período bastante antiguo, en el OIS 5, Cova Eirós proporciona evidencias directas concluyentes de actividad cazadora por la existencia de proyectiles de piedra usados e indirectas, pero no menos concluyentes, por la importante presencia de trabajo de piel seca. La piel solo se puede trabajar si se accede a ella cuando se encuentra en buen estado - completa y sin haberse iniciado la putrefacción-. Tales condiciones solo se consiguen de manera regular accediendo a las carcasas animales a través de la caza.

\section{CONCLUSIÓN}

Los sistemas de producción de utillaje de piedra puestos en práctica en el nivel 3 de Cova Eirós reflejan una gran riqueza técnica. Hay estrategias de talla de tipo unipolar, bipolar, Quina, discoide, Kombewa y Levallois -en diversas variantes: centrípeto recurrente, unipolar, para puntas y microlevallois-. Esta variabilidad responde a las condiciones de la materia prima disponible, a las características organizativas de los grupos reflejadas en la gestión del utillaje y a las necesidades complejas de utillaje en el curso de las ocupaciones o de las actividades diseñadas desde ellas.

Estos factores desembocan en una gestión diferencial en la que se combinan, de forma bastante compleja, las materias primas, las técnicas de talla y la circulación de los productos. Grosso modo se han generado dos grandes categorías de instrumental lítico. Por una parte, un conjunto de utillaje importado -toda la cuarcita y una parte del cuarzo- y para el que se aplican sistemas de talla predeterminada como el Levallois, el Quina y el discoide y una parte de la producción unipolar en cuarzo para conseguir soportes grandes de morfologías regulares o predecibles. Por otra parte, un utillaje basado en soportes de pequeño formato y producción local que aprovecha bloques de cuarzo de peor calidad con tallas unipolares, microlevallois con preparaciones mínimas o, de manera incidental, con talla Kombewa. Los soportes han sido intensamente conformados por retoque, sobre todo los de cuarzo, aunque muchos de los soportes brutos introducidos han sido aprovechados sin preparaciones ulteriores. Esto sugiere una planificación bastante cuidadosa en la circulación de estos soportes, con formatos y tamaños específicos (Lemorini 2000).

El análisis microscópico de los materiales ha constatado una aceptable conservación de las huellas de uso. El análisis traceológico permite detectar algunas de las actividades que se desarrollan en el asentamiento y, en consecuencia, son una parte relevante en la determinación de su función en las estrategias generales de explotación del territorio. En Cova Eirós se reconocen actividades variadas y complejas, algunas relacionadas con la captación y el consumo alimenticio. Otras, las más intensas y probablemente las principales en el asentamiento, están relacionadas con transformaciones tecnológicas y con la producción de objetos e instrumentos de madera y de piel.

El tipo de tareas evidenciadas supone una fuerte inversión de tiempo y esfuerzo y una gestión compleja del utillaje y del territorio en torno a este lugar. El traslado de la materia prima, la importación de soportes ya conformados y la reutilización de algunos, empleados en actividades intensivas o sobre materias muy abrasivas (raspado de piel seca en este caso), implican una estructuración espacial en la gestión de los recursos (líticos y animales) y suponen una alta planificación de los trabajos del grupo. Estas actividades son asociadas, habitualmente, a asentamientos con un cierto grado de estabilidad residencial. La proporción de elementos de proyectil con huellas de uso abunda en esta determinación. Este último rasgo dista de ser anecdótico en un contexto cronológico como el de Cova Eirós, en pleno OIS 5, más aún con las características de esta actividad cazadora reflejada en la cueva, que está perfectamente integrada en el sistema técnico, con proyectiles de piedra conseguidos con estrategias de 
talla específicas, con módulos estandarizados y dispositivos para el enmangue y con planificación para la reposición de las puntas fracturadas. Esta actividad se orienta a la obtención de aportes importantes a la dieta y de materias primas que nutren procesados técnicos estratégicos como la elaboración de productos de piel.

\section{AGRADECIMIENTOS}

Proyecto "Sondeo arqueológico en Cova Eirós y prospección arqueológica en el concello de Triacastela (Lugo)" (Xunta de Galicia, CD 102A 2008/418-0), investigadora principal Talía Lazuén, y proyecto "Ocupaciones humanas durante el Pleistoceno de la cuenca media del Miño" (MICINN, HUM/2007-63662), investigador principal Ramón Fábregas.

T. Lazuén agradece a Juan Gibaja, Ignacio Clemente (CSIC) y Jesús González Urquijo (Universidad de Cantabria) su apoyo durante el análisis funcional y el uso de las colecciones experimentales de sus laboratorios.

\section{BIBLIOGRAFÍA}

Aguirre, E. 1964: "Las Gándaras de Budiño. Porriño (Pontevedra)". Excavaciones Arqueológicas en España 31, Ministerio de Cultura. Madrid.

Ameloot-Van Der Heijden, N. 1993: "L'industrie laminaire du niveau CA du gisement paléolithique moyen de Riencourt-lès-Bapaume (Pas-de-Calais)". Bulletin de la Société Préhistorique Française 90 (5): 324-327.

Baena, J. y Cuartero, F. 2006: "Más allá de la tipología lítica: lectura diacrítica y experimentación como claves para la reconstrucción del proceso tecnológico". Zona arqueológica 7 (1): 145-160.

Bergman, C. A. y Newcomer, M. H. 1983: "Flint arrowhead breakage: examples from Ksar Akil, Lebanon". Journal of Field Archaeology 10: 238243.

Beyries, S. y Roche, H. 1982: "Technologie et traces d'utilisation: application a des industries acheuléennes (Carrières Thomas, Casablanca, Maroc)". Studia Praehistorica Belgica 2: 267-278.

Boëda, E. 1991: “Approche de la variabilité des systèmes de production lithique des industries du paléolithique inférieur et moyen: cronique d'une variabilité attendue". Techniques et culture 17-18: 37-79.
Boëda, E. 1993: Le concept Levallois: variabilité des méthodes. Monographie 9 du Centre de Recherches Archéologiques, C.N.R.S. París.

Boëda, E.; Geneste, J.-M. y Meignen, L. 1990: “Identification de chaînes operatoires lithiques du paléolithique ancien et moyen". Paléo 2: 43-80.

Boëda, E.; Bourguignon, L. y Griggo, C. 1998: “Activités de subsistance au Paléolithique moyen: couche VI3b' du gisement d'Umm el Tlel (Syrie)". En Économie préhistorique: les comportements de subsistance au Paléolithique. XVIIIe. Rencontres Internationales d'Archéologie et d'Histoire d'Antibes 1997. Ed. APDCA. Sophia Antipolis: 243-258.

Bourguignon, L. 1996: "La conception de débitage Quina". En A. Bietti y S. Grimaldi (dir.): Reduction Processes for the European Mousterian. Quaternaria Nova 6: 149-166.

Bourguignon, L. 2001: “Apports de l'expérimentation et de l'analyse techno-morpho-fonctionelle a la reconaissance du processus d'aménagement de la retouche Quina". Préhistoire et Approche Expérimentale. Préhistoire 5: 35-66.

Bracco, J.-P. 1997: “L'utilisation du quartz au Paléolithique supérieur: quelques réflexions techno-économiques". Préhistoire Anthropologie Méditerranéennes 6: 285-288.

Callow, P. y Cornford, J. (eds.) 1986: La-Cotte-deSainte-Brélade 1961-1978: Excavations by C. B. M. McBurney. Geo Books. Norwich.

Cano Pan, J. A.; Aguirre, E.; Giles, F.; Gracia, P.; Santiago, A.; Mata, E.; Gutiérrez, J. M.; Díaz, F.; Baena, R. y Borja, F. 1997: “Evolución del Pleistoceno en la cuenca baja del Miño, sector La Guardia-Tuy. Secuencia de los primeros poblamientos humanos y registro arqueológico”. En J. Rodríguez Vidal (ed.): Cuaternario Ibérico. Aequa. Huelva: 201-212.

Cano Pan, J. A.; Giles, F.; Aguirre, E.; Santiago, A.; Gracia, J.; Mata, E.; Gutiérrez, J. M. y Prieto, O. 2000: "Middle Paleolithic Technocomplexes and Lithic Industries in the Northwest of the Iberian Peninsula". En C. B. Stringer, R. N. Barton y J. Finlayson (eds.) Neanderthals on the Edge. Oxbow Books. Oxford: 49-57.

Cano Pan, J. A. y Nogueira, S. 1993: "Intervención arqueológica en Cova Eirós". Furada 1: 35-37.

Carbonell, E.; García-Antón, M. D.; Mallol, C.; Mosquera, M.; Ollé, A.; Rodríguez, X. P.; Sahnouni, M.; Sala, R. y Vergès, J. M. 1999: "The TD6 level lithic industry from Gran Dolina, Atapuerca (Burgos, Spain): production and use". Journal of Human Evolution 37: 653-693.

Carrión, E. y Baena, J. 1999: “El Habario, un yacimiento musteriense al aire libre en los Picos de Europa cántabros". Espacio, Tiempo y Forma. Serie I Prehistoria y Arqueología 12: 81-101.

Carrión, E. y Baena, J. 2003: "La producción Quina del nivel XI de la Cueva del Esquilleu: una gestión

Trab. Prehist., 68, N. ${ }^{\circ}$ 2, julio-diciembre 2011, pp. 237-258, ISSN: 0082-5638

doi: $10.3989 /$ tp.2011.11068 
especializada de la producción". Trabajos de Prehistoria 60 (1): 35-52.

Carrión, E.; Baena, J.; Conde, C.; Cuartero, F. y Roca, M. 2008: "Variabilidad tecnológica en el musteriense de Cantabria". En R. Mora, J. Martínez Moreno, I. de la Torre y J. Casanova (eds.): Variabilidad técnica del Paleolitico Medio en el sudoeste de Europa. Treballs d'Arqueologia 14. Universitat Autònoma de Barcelona. Barcelona: 279-318.

Clemente, I. y Gibaja, J. 2009: "Formation of use-wear traces in non-flint rocks: the case of quartzite and rhyolite. Differences and similarities". En F. Sternke, L. Eigeland y L.-J. Costa (eds.) Non-Flint Raw Material Use in Prehistory / L'utilisation préhistorique de matières premières lithiques alternatives Old prejudices and new directions / Anciens préjugés, nouvelles perspectives. British Archaeological Reports, International Series 1939, Archaeopress. Oxford: 135-147.

Delagnes, A.; Jaubert, J. y Meignen L. 2007: “Les techno-complexes du Paléolithique moyen en Europe occidentale dans leur cadre diachronique et géographique". En B. Vandermeersch y B. Maureille (eds.): Les Néandertaliens. Biologie et cultures. Éd. du Comité des travaux historiques et scientifiques. París: 213-229.

Dibble, H. L. y McPherron, S. 2006: "The missing Mousterian". Current Anthropology 47: 777-803.

Dockall, J. E. 1997: "Wear traces and projectile impact: a review of the experimental and archaeological evidence". Journal of Field Archaeology 24: 321-331.

Duran, J.-P. y Soler, N. 2006: "Variabilité des modalités de débitage et des productions lithiques dans les industries moustériennes de la grotte de l'Arbreda, secteur alpha (Sernyà, Espagne)". Bulletin de la Sociéte Préhistorique Francaise 103 (2): 241-262.

Estévez, J. y Vila, A. 1999: Piedra a Piedra. Historia de la construcción del Paleolítico en la Península Ibérica. British Archaeological Reports, International Series 805. Archaeopress. Oxford.

Fábregas, R.; Alonso, S.; Ameijenda, A.; Grandal, A.; Lazuén, T.; Lombera, A.; Pérez Alberti, A.; Pérez, M.; Rodríguez, X. P.; Serna, M. R. y Vaquero, M. 2010: "Completando o mapa: novas datacións absolutas para o Paleolítico e Mesolítico do interior galego". Gallaecia 29: 5-28.

Fábregas, R.; Alonso, S.; Lazuén, T.; Lombera, A.; Pérez Alberti, A.; Rodríguez, X. P.; Rodríguez Rellán, C.; Terradillos, M.; Serna, M. R. y Vaquero, M. 2008: “Aportacións ó estudo da Prehistoria da cunca media do Miño. Os asentamentos en cova e ó aire libre". Gallaecia 27: 63-88.

Fábregas, R.; Lazuén, T.; Lombera, A..; Peña, J. A.; Pérez Alberti, A.; Rodríguez, X. P.; Rodríguez Rellán, C. y Terradillos, M. 2007: "Novos achados paleolíticos no interior de Galicia. A Depresión de
Monforte de Lemos e as súas industrias líticas”. Gallaecia 26: 7-33.

Fischer, A.; Hansen, P. V. y Rasmussen, P. 1984: “Macro and Micro Wear Traces on Lithic Projectile Points". Journal of Danish Archaeology 3: 19-46.

Gaudzinski, S. 2000: "On the variability of Middle Palaeolithic procurement tactics: the case of Salzgitter Lebenstedt, Northern Germany". International Journal of Osteoarchaeology 10: 396-406.

Geneste, J. M. 1991: "Systèmes techniques de production lithique: variations techno-economiques dans les processus de realisation des outillages paléolithiques". Techniques et culture, 17-18: 1-35.

Geneste, J. M. y Plisson, H. 1993: "Hunting technologies and human behavior: lithic analysis of solutrean shouldered points". En H. Knecht, A. Pike-Tay y R. White (eds.): Before Lascaux: The complex record of the early Upper Palaeolithic. CRC Press. Nueva York: 117-135.

Gibaja, J. F. 2007: "Avance sobre la funcionalidad de las industrias líticas: análisis traceológico del utillaje lítico del nivel 14 de Cueva Bajondillo”. En M. Cortés (ed.): Cueva Bajondillo (Torremolinos). Secuencia cronocultural y paleoambiental del Cuaternario reciente en la Bahía de Málaga. Centro de Ediciones de la Diputación de Málaga, Málaga: 467-488.

Gibaja, J. F. y Clemente, I. 2009: "Experimentació i funció en instruments de producció". Cota Zero 24: 89-96.

Gibaja, J. F.; Clemente, I. y Mir, A. 2002: “Análisis funcional en instrumentos de cuarcita: el yacimiento del Paleolítico Superior de la Cueva de la Fuente Trucho (Colungo, Huesca)". En I. Clemente, R. Risch y J. F. Gibaja (eds.): Análisis funcional: su aplicación al estudio de sociedades prehistóricas. British Archaeological Reports, International Series 1073. Archaeopress. Oxford: 79-86.

González Urquijo, J. e Ibáñez, J. J. 1994: “Metodología de análisis funcional de instrumentos tallados en sílex". Cuadernos de Arqueología 14. Universidad de Deusto. Bilbao.

González Urquijo, J.; Ibáñez, J. J.; Ríos, J.; Bourguignon, L.; Castaños, P. y Tarriño, A. 2005: "Excavaciones recientes en Axlor. Movilidad y planificación de actividades en grupos de neandertales". En R. Montes y J. M. Lasheras (eds.): Neandertales cantábricos, estado de la cuestión. Museo Nacional y Centro de Investigación de Altamira. Santillana del Mar: 527-539.

Grandal, A. 1993: "El Oso de las Cavernas en Galicia: el yacimiento de Cova Eirós". Serie Nova Terra 8. O Castro. A Coruña.

Grandal, A. y Vidal, J. R. 1991: “Macromamíferos del Pleistoceno Superior de Galicia (NW de la P. Ibérica)". Cuadernos do Laboratorio Xeolóxico de Laxe 16: 7-22. 
Guette, C. 2002: "Révision critique du concept de débitage Levallois à travers l'étude du gisement moustérien de Saint-Vaast-la-Hougue/Le Fort (chantiers I-III et II, niveaux inférieurs) (Manche, France)". Bulletin de la Société Préhistorique Française 99: 237-248.

Huet, B. 2006: De l'influence des matières premières lithiques sur les comportements techno-économiques au Paléolithique moyen: l'exemple du Massifarmoricain (France). Tesis doctoral, Université de Rennes 1. http://tel.archives-ouvertes.fr/tel-00147396/en/ (consulta 12-VIII-2010).

Ibáñez, J. J. y González Urquijo, J. 1996: From tooluse to site function: use-wear analysis in some Final Upper Palaeolithic sites in the Basque country. British Archaeological Reports, International Series 658, Tempus Reparatum. Oxford.

Karlin, C. 1991: “Analyse d'un processus technique: le débitage laminaire des magdaléniens de Pincevent (Seine et Marne)". En R. Mora, X. Terradas, A. Parpal y C. Plana (eds.): Tecnología y cadenas operativas líticas. Universitat Autònoma de Barcelona. Barcelona: 125-162.

Keeley, L. H. 1980: Experimental determination of stone tool uses. A microwear analysis. The University of Chicago Press. Chicago.

Lazuén, T.; Rodríguez, X. P.; Lombera, A. y Fábregas, R. 2010: "Primeiras intervencións no xacemento de Cova Eirós, Triacastela (Lugo)". En Actuacións Arqueolóxicas, Ano 2008. Xunta de Galicia, Santiago de Compostela: 334-336.

Lemorini, C. 1999: "Hide treatment in a Middle Palaeolithic site: use-wear analysis and experimental reconstruction of the "chaînes operatoires"'. En L. R. Owen y M. Porr (eds.): Ethno-analogy and the reconstruction of prehistoric artefact use and production. Mo Vince. Tubingen: 131-140.

Lemorini, C. 2000: Reconnaître des tactiques d'explotation du milieu au paléolithique Moyen. La contribution de l'analyse fonctionelle. Étude fonctionelle des industries lithiques de Grotta Breuil (Latium, Italie) et de La Combette (Bonnieux, Vaucluse, France). British Archaeological Reports, International Series 858, Archaeopress. Oxford.

Levi-Sala, I. 1996: A study of microscopic polish on flint implements. British Archaeological Reports, International Series 629, Archaeopress. Oxford.

Lombard, M. 2005: "Evidence of hunting and hafting during the Middle Stone Age at Sibudu Cave, KwaZulu-Natal: a multianalytical approach". Journal of Human Evolution 48: 279-300.

Lombard, M.; Parfsons, I. y Van Der Ryst, M. M. 2004: "Middle Stone Age lithic experimentation for macro-fracture and residue analyses: the process and preliminary results with reference to the Sibudu Cave points". South African Journal of Science, 100: $159-166$.
Lombera, A.; Vaquero, M.; Alonso, S.; Rodríguez, X. P.; Lazuén, T. y Fábregas, R. 2008: “A cunca media no Miño dentro das ocupacións paleolíticas do NW peninsular". En E. Méndez Quintas (ed.): Homenaxe a Xose María Álvarez Blázquez (2). Estudos sobre Paleolítico. Instituto de Estudos Miñoranos. Gondomar: 321-346.

Llana, C. 1991: “Algunas consideraciones económicas del Paleolítico superior a través de los cuarzos y cuarcitas de grano grueso". Gallaecia 12: 29-38.

Márquez, B. y Baena, J. 2002: "La traceología como medio para determinar el sentido de ciertas conductas técnicas estandarizadas observadas en el registro lítico: el caso de las raederas del yacimiento musteriense de El Esquilleu (Cantabria)". En I. Clemente, R. Risch y J. F. Gibaja (eds.): Análisis funcional. Su aplicación al estudio de sociedades prehistóricas. British Archaeological Reports, International Series 1073, Archaeopress. Oxford: 133-139.

Márquez, B.; Ollé, A. y Sala, R. 1999: "Análisis microscópico de los instrumentos de Galería (Sierra de Atapuerca). Actividades desarrolladas y formas de uso". En E. Carbonell, A. Rosas y C. Diez (eds.): Ocupaciones Humanas y Paleoecología del yacimiento de Galería. Monografías Arqueológicas, Arqueología en Castilla y León, Junta de Castilla y León. Valladolid: 353-369.

Martínez, K; García, J.; Chacón, M. G. y FernándezLaso, M. C. 2005: "Le Paléolithique moyen de l'Abric Romaní. Comportements écosociaux des groupes néandertaliens". L'Anthropologie 109 (5): 815-839.

McBrearty, S.; Bishop, L.; Plummer, T.; Dewar, R. y Conard, N. 1998: "Tools Underfoot: Human Trampling as an Agent of Lithic Artifact Edge Modification". American Antiquity 63: 108-129.

Méndez Quintas, E.; Villar, R.; Santonja, M.; Pérez González, A. y Bárez, A. 2006: "Valoración preliminar del yacimiento paleolítico de Portomaior, As Neves, Galicia”. Zona Arqueológica 7 (1): 185192.

Moles, V. y Boutié, P. 2009: “Contribution à la reconnaissance d'une microproduction au Paléolithique moyen: les industries de la grotte des Ramandils (Port-La Nouvelle, Aude, France)". L'Anthropologie 113: 356-380.

Moncel, M. H. 2003: “L'exploitation des petits galets dans les assemblages microlitiques du Paléolithique moyen d'Europe centrale, Külna et Predmosti en République tchèque, Tata en Hongrie". En M. Peresani (ed.): Discoid lithic technology. Advances and implication. British Archaeological Reports, International Series 1120, Archaeopress. Oxford: 225-239.

Moncel, M. H.; Borel, A.; Lombera, A.; Sala, R. y Deniaux, B. 2008: "Quartz et quartzite dans le site de Payre (MIS 7 et 5, Ardèche, France): données

Trab. Prehist., 68, N. ${ }^{\circ}$ 2, julio-diciembre 2011, pp. 237-258, ISSN: 0082-5638

doi: $10.3989 /$ tp. 2011.11068 
techno-économiques sur la gestión de roches locales au Paléolithique moyen". Comptes Rendus Palevol 7: 441-451.

Moncel, M. H.; Chacón, M. G.; Coudenneau, A. y Fernandes, P. 2009: "Points and convergent tools in the European Early Middle Palaeolithic site of Payre (SE, France)". Journal of Archaeological Science 36: 1892-1909.

Nogueira, S. 1997: “Unha primeria aproximación o estudio dos materiais líticos de Cova Eirós (Triacastela-Lugo)". Historia Nova IV: 9-29.

Odell, G. H. y Cowan, F. 1986: "Experiments with spears and arrows on animal targets". Journal of Field Archaeology 13: 195-212.

Ollé, A.; Vergés, J. M. y Galiberti, A. 1999: “A preliminary microwear study of Acheulean artefacts from three Italian sites: Due Pozzi, Peverella and Crotta Paglicci”. En A. R. Cruz, S. Milliken, L. Osterbeek y C. Peretto (eds.): Human Population Origins in the Circum Mediterranean Area: Adaptations of the Hunter-Gatherer Groups to Environmental Modifications. Arkeos 5, Centro Europeu de Investigaçào da Pré-História do Alto Ribatejo, Tomar: 255-266.

Pant, R. K. 1989: "Étude microscopique des traces d'utilisation sur les outils de quartz de la Grotte de l'Arago, Tautavel, France'. L'Anthropologie 93: 689-704.

Pelegrin, J.; Karlin, C. y Bodu, P. 1988: "Chaînes opératoires': un outil pour le préhistorien". En J. Tixier (ed.): Technologie Préhistoriques. Notes et monographies techniques 25. CNRS. París: 55-62.

Peresani, M. (ed.) 2003: Discoid Lithic Technology. Advances and Implications. British Archaeological Reports, International Series 1120, Archaeopress. Oxford.

Plisson, H. y Beyries, S. 1999: "Pointes ou outils triangulaires? Données fonctionnelles dans le Moustérien levantin". Paléorient 24: 5-24.

Plisson, H. y Geneste, M. 1989: "Analyse technologique des pointes à cran solutréennes du Placard (Charente), du Fourneau du Diable, du Pech de la Boissière et de Combe Saunière (Dordogne)". Paléo 1: 65-106.

Plisson, H. y Mauger, M. 1988: “Chemical and mechanical alteration of microwear polishes: an experimental approach". Helinium 28 (1): 3-16.

Prost, D. C. 1987: "Essai de étude sur les mecanismes d'enlevement produits par les façons agricoles et le pietinement humain sur des silex experimentaux". En S. Beyries (ed.): Industries Lithiques. Tracéologie et Technologie II. British Archaeological Reports, International Series 411, Archaeopress. Oxford: 49-64.

Ríos, J. 2008: "Variabilidad tecnológica en el Paleolítico Medio de los Pirineos Occidentales: una expresión de las dinámicas históricas de las sociedades neandertales". En R. Mora, J. Martínez Moreno, I. de la Torre y J. Casanova (eds.): Variabilidad técnica del Paleolítico Medio en el sudoeste de Europa. Treballs d'Arqueologia 14, Universitat Autònoma de Barcelona. Barcelona: 171-194.

Roebroeks, W. 2001: "Hominid behaviour and the earliest occupation of Europe: An exploration". Journal of Human Evolution 41 (5): 437-461.

Santanach, P. 1994: "Las cuencas terciarias gallegas en la terminación occidental de los relieves pirenaicos". Cuadernos do laboratorio Xeolóxico de Laxe 19: 57-71.

Shea, J. J. 1988: "Spear points from the middle paleolithic of the Levant". Journal of Field Archaeology 15: 441-451.

Shea, J. J. 1989: "A functional study of the lithic industries associated with hominid fossils in the Kebara and Qafzeh Caves, Israel". En P. Mellars y C. Stringer (eds.): The human revolution: behavioral and biological perspectives on the origin of modern human. Edinburgh University Press. Edimburgo: 611-625.

Shea, J. J. 1993: "Lithic use-wear for hunting in the Levantine Middle Paleolithic". En P. C. Anderson, S. Beyries, M. Otte y H. Plisson (eds.): Traces et fonction: le geste retrouvé. Études et Recherches Archéologiques de l'Université de Liège 50, Université de Liège. Lieja: 21-30.

Shea, J. J. 2006: "The origins of lithic projectile point technology: evidence from Africa, the Levant, and Europe". Journal of Archaeological Science 33: $823-846$.

Shea, J. J.; Brown, K. S. y Davis, Z. J. 2002: “Controlled experiments with Middle Palaeolithic spear points: Levallois points". En J. R. Mathieu (eds.): Experimental Archeology. Replication past objects, behaviors and processes. British Archaeological Reports, International Series 1035, Archaeopress. Oxford: 55-72.

Shea, J. J. y Klenck, J. D. 1993: “An Experimental Investigation of the Effects of Trampling on the Results of Lithic Microwear Analysis". Journal of Archaeological Science 20: 175-194.

Soressi, M. 1999: "Variabilité Technologique au Moustérien. Analyse comprarée du débitage Levallois MTA A du Moustier (Dordogne, France)". Paléo 11: 111-134.

Sussman, C. 1985: "Microwear on quartz: fact or fiction?”. World Archaeology 17 (1): 101-111.

Sussman, C. 1987: 'Resultats d'une etude des microtraces d'usure sur un echantillon d'artefacts d'Olduvai (Tanzanie)". L'Anthropologie 91 (2): 375-380.

Sussman, C. 1988: A Microscopic analysis of usewear polish formation on experimental quartz tools. British Archaeological Reports, International Series 395, Archaeopress. Oxford. 
Taboada, M. T. y Silva, B. M. 1999: Factores de formación y propiedades de los suelos formados sobre calizas en Galicia. Cuadernos do laboratorio Xeolóxico de Laxe 24: 121-139.

Terradas, X. 2001: La gestión de los recursos minerales en las sociedades cazadoras-recolectoras. Treballs d'Etnoarqueologia 4. CSIC. Madrid.

Terradas, X. 2003: "Discoid flaking method: conception and technological variability". En M. Peresani (ed.): Discoid Lithic Technology. Advances and Implications. British Archaeological Reports, International Series 1120, Archaeopress. Oxford: 19-31.

Tixier, J. y Turq, A. 1999: "Kombewa et alii". Paléo 11: $135-143$.

Vázquez Varela, J. M. 2000: "El Paleolítico en el noroeste de la Península Ibérica. Spal 9: 69-79.

Vergés, J. M.; Ollé, A.; Longo, L. y Peretto, C. 1999: "Microwear analysis of the Lower Pleistocene lithic industry of Monte Poggiolo (Forli, Italy)". En A. R. Cruz, S. Milliken, L. Osterbeek y C. Peretto (eds.): Human Population Origins in the Circum Mediterranean Area: Adaptations of the Hunter-Gatherer Groups to Environmental Modifications. Arkeos 5, Centro Europeu de Investigaçào da Pré-História do Alto Ribatejo, Tomar: 243-253.

Villa, P. y Lenoir, M. 2009: "Hunting and Hunting Weapons of the Lower and Middle Paleolithic of Europe". En J. J. Hublin y M. P. Richards (eds.): The Evolution of Hominin Diets. Integrating Approaches to the Study of Palaeolithic Subsistence. Springer. Dordrecht: 59-85.

Villa, P.; Boscato, P.; Ranaldo, F. y Ronchitelli, A. 2009: "Stone tools for the hunt: points with impact scars from a Middle Paleolithic site in southern Italy". Journal of Archaeological Science 36: 850859. 